\title{
Sovereign risk and belief-driven fluctuations in the euro area
}

\author{
Giancarlo Corsetti, Keith Kuester, André Meier, and Gernot J. Müller*
}

November 1, 2013

\begin{abstract}
Sovereign risk premia in several euro area countries have risen markedly since 2008, driving up credit spreads in the private sector as well. We propose a New Keynesian model of a two-region monetary union that accounts for this "sovereign risk channel." The model is calibrated to the euro area as of mid-2012. We show that a combination of sovereign risk in one region and strongly procyclical fiscal policy at the aggregate level exacerbates the risk of belief-driven deflationary downturns. The model provides an argument in favor of coordinated, asymmetric fiscal stances as a way to prevent self-fulfilling debt crises.
\end{abstract}

Keywords: Sovereign risk channel, monetary union, euro area, zero lower bound, risk premium, pooling of sovereign risk

JEL-Codes: F41, F42, E62

\footnotetext{
${ }^{*}$ Corsetti: Cambridge University and CEPR, Kuester: University of Bonn, Meier: International Monetary Fund, Müller: University of Bonn and CEPR. Prepared for the 2013 Carnegie-NYU-Rochester Conference on Fiscal Policy in the Presence of Debt Crises. We thank our discussant Enrique Mendoza and other conference participants for helpful comments. We also thank Luc Eyraud, Lorenzo Forni, Thierry Tressel, as well as seminar participants at the Bank of Italy, Federal Reserve Bank of Philadelphia, Trinity College Dublin, University of Mainz, and the WGEM Workshop on Heterogeneity and Multi-Country Modeling. The views expressed herein are those of the authors and do not necessarily represent those of the IMF.
} 


\section{Introduction}

At the height of the euro area crisis in mid-2012, a profound economic divide was opening up between member states, raising doubts about the very survival of the monetary union. In the stressed economies with weaker fundamentals, elevated sovereign risk was weighing on private credit markets and contributing to very tight financial conditions (see, for example, Lane 2012, ECB 2012, and IMF 2013). Even though the period of acute financial stress appears to have ended, borrowing costs remain elevated in the stressed economies, holding back economic activity and compounding the fiscal challenges in these countries.

In this paper, we analyze the implications of sovereign risk for macroeconomic stability in a currency union, using a stylized monetary model calibrated to the euro area. Our focus is on instability caused by self-fulfilling expectations of an economic downturn, that is, situations in which the equilibrium is not uniquely determined. As is well understood, such equilibrium indeterminacy can arise if policy rates remain constant for an extended period of time, for example, due to the zero lower bound (ZLB). In the following, we analyze the conditions under which a sovereign debt crisis in one part of the currency union exacerbates this risk of indeterminacy, making the entire union vulnerable to a belief-driven deflationary downturn. Our theoretical framework is a two-country version of the New Keynesian model considered in Corsetti et al. (2013). In the model, government debt is not risk-free, and sovereign risk premia increase nonlinearly as the fiscal outlook of a country deteriorates. Heterogeneous households engage in borrowing and lending through financial intermediaries as in Cúrdia and Woodford (2009). We assume that the prevailing private-sector credit spread rises with sovereign risk, because strained public finances increase the cost of financial intermediation. The link between sovereign risk and private spreads creates a "sovereign risk channel" for the transmission of macroeconomic shocks. This channel may be unimportant during normal times, since the central bank can adjust policy rates to contain effective borrowing costs. However, sovereign risk becomes highly consequential when, as in the recent euro area experience, monetary policy is expected to be constrained by the ZLB for an extended period.

We calibrate our analysis to the euro area, with specific reference to the monetary, fiscal, and 
financial conditions of mid-2012. On the one hand, mid-2012 marked the most recent climax of the euro area crisis, when intense market stress brought to light the growing economic divide between stressed and other economies. One critical dimension of that divide was perceived sovereign risk, as underpinned by a level difference in government indebtedness. In the stressed economies, government debt, including estimates of contingent liabilities related to ailing financial sectors, exceeded 125 percent of GDP, considerably more than the about 90 percent of GDP in the rest of the euro area. On the other hand, mid-2012 marked the establishment of two important institutional initiatives, namely, the European Stability Mechanism (ESM) and the ECB's Outright Monetary Transactions (OMT). Although the two initiatives serve distinct purposes, each has been interpreted as a way to overcome the euro area crisis through a partial, perhaps, pooling of sovereign risk. Indeed, calculations show that full use of the scope provided by ESM and OMT could hypothetically even erase all the differences in government indebtedness between stressed and other economies. In practice, use of the ESM has been limited to date, and the ECB has yet to make a single bond purchase under its OMT framework. Still, the mere creation of the framework has already had a significant stabilizing effect on financial markets, pointing to the strength of the underlying pledge.

In our calibration, we compare the pre-pooling to a hypothetical post-pooling scenario, under different assumptions for the cyclical stance of fiscal policy. At the pre-pooling levels of debt, the equilibrium in our baseline model is uniquely determined if the high-debt countries (are expected to) pursue a procyclical spending policy, and/or if the lower-debt countries pursue a countercyclical policy. In fact, determinacy is most readily assured when, in a recession, budget cuts in the stressed economies are matched by fiscal expansion in the rest of the union. Intuitively, procyclical austerity in the high-debt countries counteracts the effect of a beliefdriven downturn on the government budget, thus averting the rise in sovereign and privatesector risk premia that could validate an initial adverse shift in expectations. Meanwhile, countercyclical expansion in the rest of the euro area addresses the negative demand effects of government spending cuts in the stressed economies via crowding-in effects, which tend to be high when policy rates are tied to the ZLB (see, for instance, Christiano et al. 2011 
and Woodford 2011). However, a large fiscal multiplier also explains why the equilibrium is not uniquely determined when both parts of the monetary union pursue a policy of strong procyclical austerity.

Since risk premia rise nonlinearly in the level of debt, pooling of sovereign risk induces a fall in effective borrowing costs in the stressed economies that is only partially offset by higher risk premia in the other countries. The result is a less severe sovereign risk channel, which in principle relaxes the constraint that macroeconomic stability imposes on fiscal policy. Nonetheless, we find that risk pooling does not make the economy immune to any fiscal stance: in our baseline calibration with pooled debt and a common fiscal stance, equilibrium still is not uniquely determined if fiscal policy at the union level remains too strongly procyclical. Our analysis underscores the importance of monetary conditions for how fiscal policy affects the economy - a point recently emphasized by research on the fiscal multiplier at the ZLB, notably by Woodford (2011). We focus on the interaction of fiscal policies, sovereign risk, and the ZLB constraint. In this context, we find that small changes in the horizon over which policy rates are constrained by the ZLB can determine the switch from stability to instability, unless governments in high-debt countries systematically enact sharp procyclical budget cuts during recessions.

Several aspects of our analysis have been addressed from different perspectives in the related literature. In particular, we note that the present paper is not meant to add to the theory of sovereign default. Following Eaton and Gersovitz (1981), a number of authors, including Arellano (2008) and Mendoza and Yue (2012), have recently modeled default as a strategic decision of a sovereign that balances the gains from foregone debt service against the costs of exclusion from international credit markets and output losses. In equilibrium, this implies that the probability of default increases in the level of debt. In order to maintain the tractability of our model for business cycle analysis, we impose such a relationship without explicitly modeling a strategic default decision. Specifically, we link the sovereign risk premium to the expected path of public debt (or, alternatively, to future fiscal deficits).

In addressing self-fulfilling expectations as a source of macroeconomic instability, our focus on local determinacy is distinct from equilibrium multiplicity of the kind analyzed by Calvo 
(1988) and Cole and Kehoe (2000). This also implies that our analysis does not capture all aspects of the crisis-response measures recently taken in the euro area. The ECB's OMT, in particular, can be interpreted as providing a monetary backstop that rules out self-fulfilling market shutdowns via a credible, off-equilibrium strategy of bond purchases, as discussed by Corsetti and Dedola (2013); see also Aguiar et al. (2012). By contrast, we focus here on the combined impact of ESM and OMT on the pooling of government debt-a prominent dimension of many proposals to resolve the euro area crisis.

Regarding the effects of sovereign risk on economic activity, we choose a New Keynesian model in which, due to nominal rigidities, rising risk premia may directly weigh on aggregate demand and hence output. Other transmission channels have been proposed elsewhere. In Mendoza and Yue (2012), for instance, output losses are linked to firms that rely on external finance to import highly productive inputs from abroad. Financial disruptions around a default event raise the effective costs of these inputs, causing firms to replace them with less productive domestic substitutes. Acharya et al. (2013) focus on the loop between sovereign risk and bank credit risk. In their model, a bailout of financial intermediaries weighs on the budget and thus raises the probability of sovereign default. This in turn reduces collateral values and exacerbates debt overhang problems in the private sector, hampering investment. Notwithstanding these potentially important additional channels of transmission, our own analysis suggests that, at the ZLB, standard aggregate demand channels can play a critical role in propagating and amplifying the disruptive effects of fiscal stress.

The rest of the paper is organized as follows. Section 2 presents the empirical observations that inform and motivate our subsequent model-based analysis. In particular, we provide evidence for the sovereign risk channel, document recent changes in the fiscal stance of the euro area, and estimate the maximum scope for effective debt pooling under the current institutional arrangements. Section 3 presents our formal model. Section 4 provides a detailed account of the transmission mechanism under a sovereign risk channel, deriving analytical results based on a simplified version of the model. Section 5 presents our main results, based on a full-fledged numerical analysis. Section 6 concludes. 


\section{Financial conditions and policy measures in the euro area}

The euro area has witnessed four macroeconomic developments in recent years that are directly relevant to the analysis of this paper: a rise in sovereign risk premia, a related increase in private-sector risk premia, an unusually constrained central bank, and a shift toward areawide fiscal austerity. As will become clear in our model-based analysis below, these developments taken together pose a considerable threat to macroeconomic stability. In this section, we briefly document each of the four developments in turn.

Throughout, we divide the member states of the euro area into two groups: the "stressed" economies, which include Cyprus, Greece, Ireland, Italy, Portugal, Slovenia, and Spain, and the rest, which includes the other ten euro area member states. ${ }^{1}$ The two groups account for one third and two thirds of euro area output, respectively.

\section{$2.1 \quad$ Evidence on the sovereign risk channel}

This section documents the first two of the developments mentioned above: the rise in sovereign spreads and their apparent spillover to private-sector borrowing conditions. Toward this end, Figure 1 displays time series on credit default swap (CDS) spreads for government debt (dashed red line) and nonfinancial corporate debt (solid blue line). The right panel refers to the stressed economies, the left panel to the rest of the euro area.

From 2010 through mid-2012, sovereign CDS spreads rose markedly in the stressed economies, but fairly little elsewhere. The same divergence is also apparent for the funding conditions of nonfinancial corporate borrowers from the respective regions. ${ }^{2}$ As financial stress started to abate in the second half of 2012 , sovereign spreads in the stressed economies fell and so again did the credit spreads in the nonfinancial corporate sector. Figure 1, thus, points to a systematic relationship between the two series that is consistent with strong spillovers from sovereign distress to private-sector financial conditions. Specifically, fears about potential sovereign default - whether within the euro area or following a disorderly exit, which was

\footnotetext{
${ }^{1}$ Our approach closely follows the delineation between "core" and "periphery" in other publications, such as IMF (2013, p. 6). One formal way of defining the two groups is based on the criterion of a sovereign CDS spread below/above 150 basis points.

${ }^{2}$ For the entire time period shown, the daily correlation between sovereign and corporate CDS spreads in the stressed economies is 0.83 . For the other countries, it is lower, but still positive at 0.34 .
} 

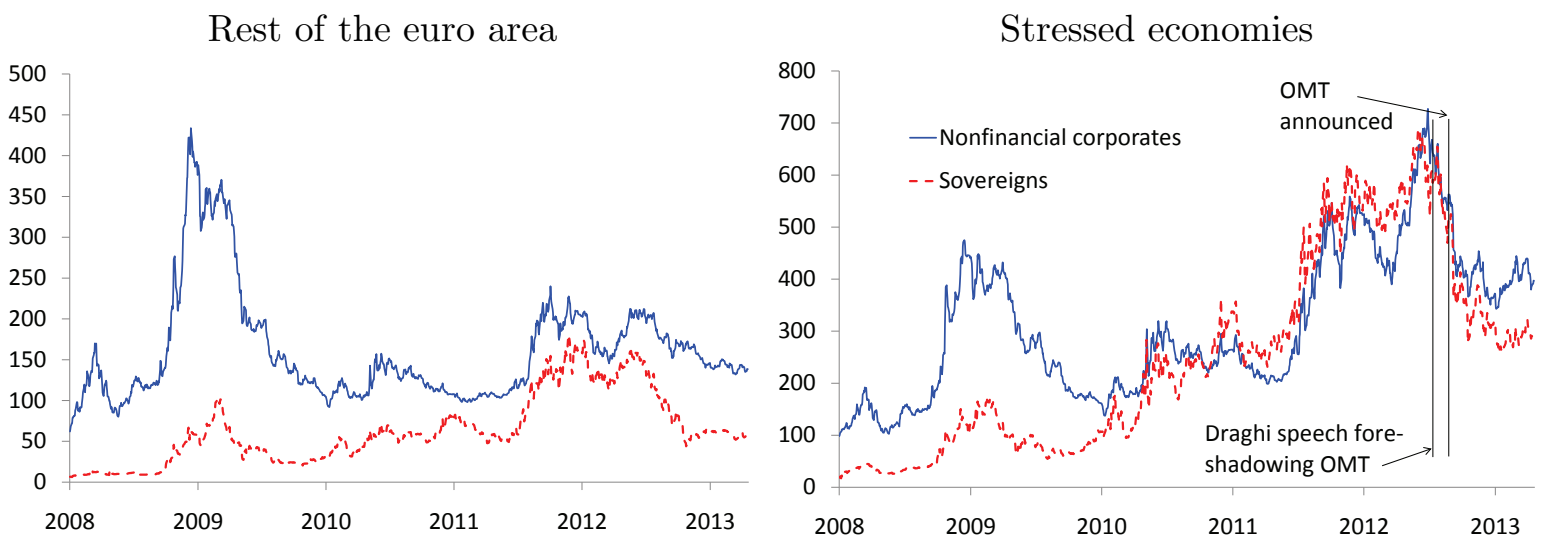

Notes: 5-year CDS spreads in the euro area stressed economies vs. the rest of the euro area. The figure shows spreads for sovereigns (dashed) and for nonfinancial corporations headquartered in the respective country group (solid). Corporate data for the stressed economies include observations for Italy (number of firms in the sample: 4), Portugal (2), and Spain (6). The sample of other economies includes Austria (1), Finland (4), France (29), Germany (21), and the Netherlands (8). The same relative weights are adopted for the sovereign and corporate index series. For example, of the 63 firms in the 'rest of the euro area' sample, 29 are headquartered in France. As a result, in the sovereign series for this sample, France has a weight of 29/63. The corporations in our sample are the constituents of the Markit iTraxx Europe index. Data source: Bloomberg.

widely considered as a tail risk in early 2012 - can cause a general retrenchment of private credit, as potential lenders worry about broad-based economic disruption. ${ }^{3}$ This "sovereign risk channel" will be a key ingredient of the model we present below.

A large body of literature supports the notion of a sovereign risk channel. Neri (2013), for example, estimates that, between April 2010 and the end of 2011, sovereign spreads in the crisis countries led to an increase in borrowing costs for nonfinancial firms and households by 130 and 60 basis points, respectively. For Italy (the largest of the stressed economies), Zoli (2013) finds that some 50-60 percent of the increase in sovereign spreads is transmitted to firms' borrowing rates within six months; see also Albertazzi et al. (2012), Neri and Ropele (2013), and the literature reviews in Cavallo and Valenzuela (2007) or Harjes (2011). ${ }^{4}$

\footnotetext{
${ }^{3}$ Figure 1 is likely to understate the extent of such spillovers, as the corporate sample under consideration includes only the largest firms with usually good access to capital markets and often significant foreign operations. As the recent experience in the euro area confirms, smaller companies tend to face much tighter funding conditions during times of domestic financial stress, especially when such stress affects the banking system, on which they typically rely for credit.

${ }^{4}$ Our focus on spillovers from sovereigns to nonfinancial corporates is not meant to suggest that the relationship is unidirectional. Clearly, government support to the financial sector (as analyzed in Kollmann et al.
} 

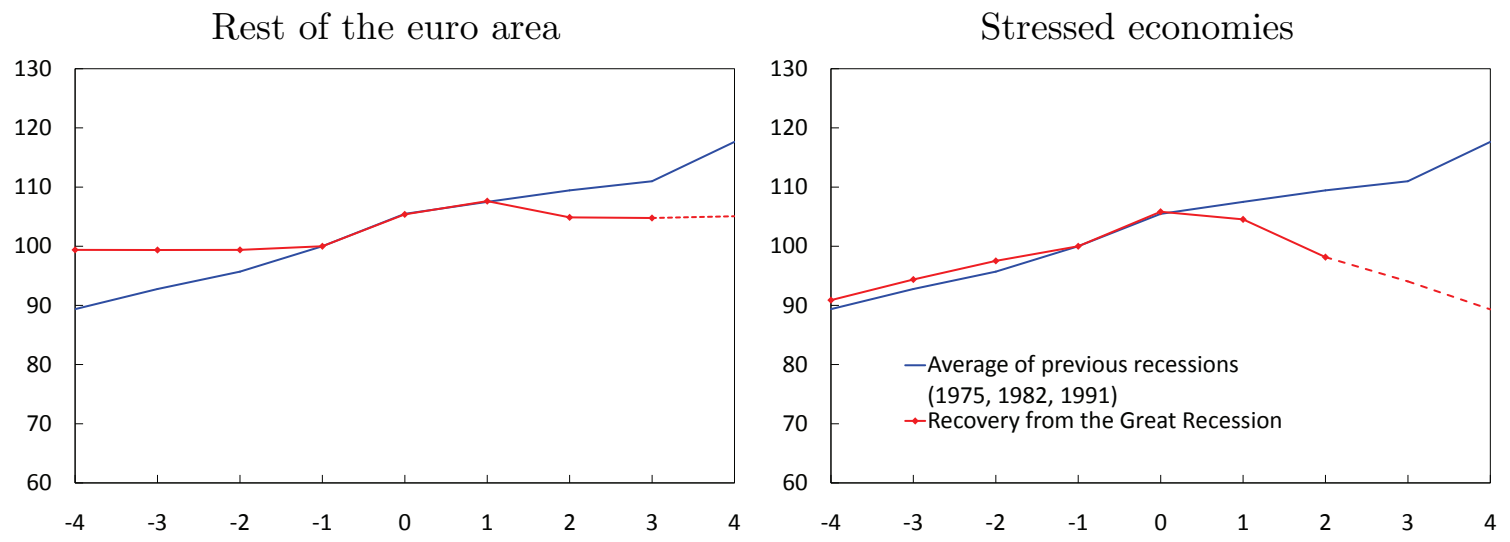

Notes: Horizontal axis shows years from global recession. Vertical axis shows real primary government expenditure; index $=100$ in the year before the global recession. Dashed lines denote IMF projections. Aggregates are purchasing-power-parity weighted. Stressed economies include Greece, Ireland, Italy, Portugal, and Spain. Rest of the euro area includes France and Germany. Source: IMF, World Economic Outlook April 2013, Figure 1.1 .2 .

\section{$2.2 \quad$ Fiscal and monetary policy}

Our model will emphasize that in the presence of the sovereign risk channel, macroeconomic stability is even more dependent than usual on the specifics of fiscal and monetary policy interaction. In order to put our results into an appropriate context, we now provide a brief characterization of fiscal and monetary policy since the beginning of the crisis.

\subsubsection{A shift toward procyclical fiscal policy}

As regards fiscal policy, most euro area governments ran sizable budget deficits during the early stages of the global financial crisis. By 2010, however, with government debt and sovereign risk premia on the rise, both the stressed and the other economies shifted to a procyclical fiscal stance characterized by substantial real spending cuts in the midst of an (area-wide) downturn. Figure 2 illustrates the unusual nature of this shift toward fiscal

(2012), among others) or broader weakness among corporates may jeopardize the health of public finances; see also Acharya et al. (2013). In fact, our model includes a feedback channel through which a weakened corporate sector further compounds the sovereign's fiscal challenges. However, our primary interest is in the extent to which sovereign weakness itself can induce macroeconomic instability - a constellation that strikes us as highly relevant to the recent experience of economies like Italy. 
austerity. It compares the evolution of real primary government expenditure before and after the global recession of 2009 , with the developments in the previous three global recessions. ${ }^{5}$ The figure makes it clear that fiscal policy in the euro area since 2010 has been much tighter than usual at this stage of the cycle. Furthermore, the tight stance is expected to persist, particularly in the stressed economies.

Figure 3: Eonia and Eonia OIS-based forward curve (as of July 31, 2012)

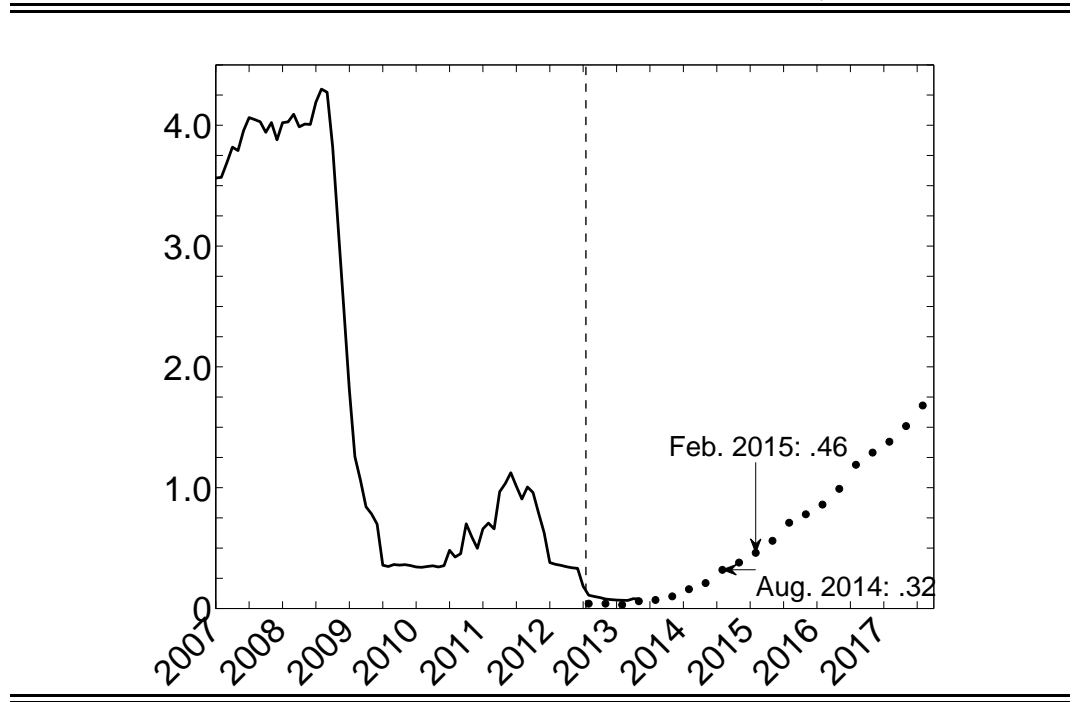

Notes: Data source: Bloomberg; ECB Statistical Data Warehouse. The solid line shows monthly averages of Eonia rates from January 2007 through May 2013. Dots mark Eonia OIS-based forward rates as of July 31, 2012. A dashed vertical line marks this cutoff date. All entries are in percent.

\subsubsection{Interest rates at the zero lower bound}

The last building block in this paper is the central bank's monetary stance. In reaction to the crisis, the ECB has cut its policy rates to record-low levels, driving overnight money market rates down to basically zero. Thus, Figure 3 shows that by mid-2012 the ECB had largely exhausted its capacity to provide accommodation through conventional monetary policy. The figure depicts the evolution of the overnight rate (Eonia, monthly averages) through May 2013 as a solid line, along with market-based expectations of future Eonia rates as of the end of

\footnotetext{
${ }^{5}$ The presentation follows IMF, World Economic Outlook April 2013. The concept of total primary expenditure considered there is broader than the notion of exhaustive government spending featured in our model below. However, the qualitative behavior of the two series during the 2009 recession was similar, as government cuts were typically broad-based.
} 
July 2012 as a dotted line. The cutoff at the end of July 2012 is chosen on purpose: it coincides with the announcement of additional nonstandard monetary policy measures, the details of which are discussed in Section 2.3 below.

The figure is consistent with the finding in Corsetti et al. (2013) that episodes of ultra-low interest rates may last for a significant time in the presence of elevated sovereign risk. Indeed, the imputed Eonia forward rates shown in Figure 3 suggest that market participants expected overnight rates to be at, or very close to zero, for at least another eight to ten quarters. ${ }^{6}$

\subsection{Nonstandard measures: Toward a partial pooling of sovereign risk}

The euro area remains characterized by disagreement on the appropriate degree of fiscal risk-sharing within the union. Notwithstanding this disagreement, measures taken since the beginning of the crisis have created scope for some pooling of debt, as will be argued in detail below. Abstracting from (obviously important) incentive effects and distributional concerns, the rationale for such pooling is straightforward. Fiscal stress in one region can jeopardize the stability of the union as a whole. To the extent that the risk of fiscal stress rises disproportionately with the debt level, the pooling of liabilities across the union can reduce the union-wide level of fiscal stress.

In the following, we focus on two policy innovations that can be interpreted in this light, namely, the ESM and the ECB's OMT. Both had been announced or at least foreshadowed by the end of July 2012 and were formally established later that year. The right panel of Figure 1 marks the OMT-related events, which appear particularly important. Specifically, the first vertical line refers to ECB President Draghi's announcement on July 26, 2012 "to do whatever it takes to preserve the euro," which foreshadowed a new bond purchase program. The second vertical line marks the formal announcement of the OMT in September 2012. The ESM, in turn, was inaugurated on October 8, 2012, following an extensive ratification process. These developments in mid-2012, and especially the ECB's communication regarding OMT, prompted a sharp and persistent fall in risk premia across the stressed economies in the euro area, albeit not fully back to pre-crisis levels. We therefore discuss in detail the scope

\footnotetext{
${ }^{6}$ Empirically, Eonia forwards tend to reflect the expected path of future rates with some upward bias, especially at longer horizons. This is due to the presence of positive term premia.
} 
and implications for fiscal risk-sharing of both the ESM and the OMT. In Section 5 below, we will analyze to what extent such risk-sharing may indeed be supportive of macroeconomic stability.

The ESM allows sovereigns facing market pressures to obtain, under certain conditions, a loan that is backed by the credit of other euro area members. As such, the ESM can be interpreted as a partial transfer of creditworthiness from stronger to weaker economies. The scale of this risk transfer depends on the actual utilization of the ESM, which has remained limited to date. It seems plausible, however, to assume that the possibility of tapping the ESM may provide a considerable benefit to countries struggling with elevated risk premia. Accordingly, we treat the ESM's maximum lending capacity as one aspect of tentative risk pooling in the euro area. The ESM's debt is backed by capital contributions from euro area member states according to their shares in the capital of the ECB. Although the upfront commitment of capital was limited to EUR 80 billion, the ESM's maximum potential lending capacity amounts to a much larger EUR 500 billion. Adding the capacity of the euro area's earlier (temporary) rescue fund, the European Financial Stability Facility (EFSF), the total reaches EUR 700 billion (see ESM, 2013). This latter sum amounts to about 7 percent of euro area GDP, or 22 percent of the stressed economies' GDP.

The ECB's OMT framework, in turn, serves the stated purpose of restoring a uniform transmission mechanism for the common monetary policy. While this mimics the objective of an earlier ECB bond purchase program (the Securities Markets Program, or SMP), the OMT scheme was designed to have a more powerful impact. ${ }^{7}$ It foresees potentially open-ended ECB purchases of government paper with a remaining maturity of 1 to 3 years, meaning that purchases are limited only by the amount of debt outstanding in that maturity bracket. Table 1 summarizes the relevant data as of early 2013, treating all debt maturities in 2014 and 2015 as falling within the relevant maturity interval. Although no actual purchases have been made to date, the scope for OMT is evidently large. Based on the debt figures shown in Table 1, potential bond purchases for stressed economies alone exceed EUR 640 billion or

\footnotetext{
${ }^{7}$ Under the SMP, which was launched in May 2010 and closed in September 2012, the eurosystem bought some EUR 220 billion (equivalent to about 2 percent of euro area GDP) in government bonds issued by Greece, Ireland, Italy, Portugal, and Spain.
} 
20 percent of the formers' GDP. The ECB has clarified that claims acquired through OMT will rank pari passu with other creditor claims. The OMT program thus inevitably involves a transfer of fiscal risks. ${ }^{8}$ In what follows, we specifically focus on this dimension, interpreting the OMT program in terms of its potential contribution to the pooling of government debt in the euro area. We already note, however, that this interpretation does not capture all aspects of the OMT program, notably its nature as a monetary backstop as analyzed in detail by Corsetti and Dedola (2013).

To quantify the extent of potential sovereign risk transfers through ESM and OMT, wherever possible, we take the vantage point of mid-2012, that is, before either the ESM or the OMT program had become operational. For debt and GDP data we draw on the IMF's WEO database of April 2012. ${ }^{9}$ At that point, the IMF projected the debt levels (the stock of general government debt outstanding) for end-2012 at 109.0 and 80.5 percent of GDP, respectively, in the stressed economies and the rest of the euro area. In addition to these explicit liabilities, we include contingent liabilities related to potential support for the domestic financial sector, based on the estimates by Arslanalp and Liao (2012). These contingent liabilities add another 17 and 12 percentage points of GDP to the liabilities of the stressed and other economies, respectively.

In computing how the ESM and OMT could potentially affect the liabilities in the two parts of the union, we assume that both the stressed and the other economies become liable for a fraction of the total relevant exposure, corresponding to their share in the ECB's capital (37 and 63 percent for the stressed and other economies, respectively).

To determine the hypothetical maximum scope for sovereign risk pooling, we assume that the ESM and the ECB will only acquire exposures to the stressed economies of the euro area. Regarding the ESM, this implies potential exposures for the other countries of some EUR 440 billion (63 percent of the total EFSF/ESM lending envelope of EUR 700 billion), or 7 percent

\footnotetext{
${ }^{8}$ Proponents of the program view this transfer of risks as central for resolving the euro area crisis. Critics disagree on the costs and benefits of such a policy but tend to agree with the basic notion that ECB purchases of government bonds constitute a partial pooling of sovereign risk. In order to address concerns about moral hazard, the ECBs readiness to conduct OMT is subject to conditionality as established under EFSF/ESMsponsored adjustment programs.

${ }^{9}$ In Table 1 we consider data for debt as of February 2013, as historical data were not available to us. Changes relative to mid-2012 should be small in any case.
} 
Table 1: Debt maturing in 2014 and 2015

Billions of euro Percent of total debt $\underline{\text { Percent of } 2012 \text { GDP }}$

Rest of the euro area

\begin{tabular}{lrrr}
\hline France & 253.1 & 18.6 & 12.2 \\
Germany & 243.0 & 21.8 & 9.2 \\
Belgium & 60.1 & 17.7 & 15.9 \\
Netherlands & 80.2 & 25.4 & 13.2 \\
Austria & 39.6 & 19.4 & 12.7 \\
Finland & 14.6 & 17.2 & 7.5 \\
Slovak Republic & 8.0 & 23.0 & 11.2 \\
Luxembourg & - & 0.0 & - \\
Malta & 0.7 & 17.4 & 11.2 \\
Estonia & 0.0 & 3.5 & 0.0 \\
\hline Total & 699.4 & 20.2 & 11.0 \\
\hline & & & \\
Stressed economies & 369.2 & 22.6 & 23.5 \\
\hline Italy & 199.9 & 27.0 & 18.8 \\
Spain & 22.8 & 7.9 & 11.0 \\
Greece & 35.1 & 19.1 & 20.9 \\
Portugal & 11.4 & 7.9 & 7.2 \\
Ireland & 2.9 & 16.8 & 8.1 \\
Slovenia & 2.4 & 24.4 & 13.0 \\
Cyprus & 643.6 & 21.3 & 20.0 \\
\hline Total & & & \\
\hline
\end{tabular}

Source: Bloomberg as of Feb. 4, 2013, and IMF WEO (April 2012). Debt maturities as reported in Bloomberg, while GDP data are taken from the IMF. Note that the sum of all debt maturities reported by Bloomberg tends to be lower than the IMF's estimates of government debt outstanding (used below). There are several potential explanations, including (i) the focus in Bloomberg on debt securities, which implies incomplete coverage of bank loans extended to the government; (ii) broader coverage of the government sector in the IMF's data; and (iii) different accounting treatment. None of these differences, however, matter for the purposes of determining the maximum amount of OMT purchases. 
Table 2: Government debt under different pooling assumptions (percent of GDP)

\begin{tabular}{lrrrr}
\hline & \multicolumn{3}{c}{ assuming full debt transfer after pooling } \\
\cline { 3 - 5 } & no pooling & ESM only & OMT only & ESM and OMT \\
\hline Rest of the euro area & 92.5 & 99.4 & 98.8 & 105.8 \\
Stressed economies & 126.0 & 112.4 & 113.4 & 99.9 \\
\hline
\end{tabular}

Notes: Figures refer to end-2012 and are expressed in percent of GDP. "Before pooling" refers to general government debt as projected in the IMF's April 2012 WEO, plus contingent liabilities related to financial sector support as estimated by Arslanalp and Liao (2012).

of the group's GDP. The amount of stressed economies' debt eligible for OMT, in turn, is about EUR 640 billion (see Table 1). Under the above assumptions, a full-blown program of OMT bond purchases could raise the exposure of the rest of the euro area by about EUR 400 billion (63 percent of the total exposure), or 6.3 percent of its GDP. In the highly unlikely event of a full write-down on all these exposures, the liabilities of the stressed economies would fall accordingly, namely, by 13.6 percent of GDP for the ESM and 12.5 percent of GDP under OMT, respectively.

Table 2 summarizes the implied maximum scope for the pooling and transfer of government debt between the stressed and the other economies. It bears repeating that a fiscal transfer of the extent shown in the table remains extremely unlikely under the current institutional setup. Yet, it is striking to see that, under the assumptions above, the government liabilities of the rest of the euro are could increase to the point of slightly exceeding those of the stressed economies. In our model-based analysis below, we will formally evaluate the importance of the inherent risk-sharing, by considering an illustrative 'debt pooling' scenario. In that scenario, we assume for simplicity that risk-sharing effectively equalizes the indebtedness (in relation to GDP) of sovereigns in the two parts of the union. The above calculations serve to show that this is actually within the potential scope of the programs that have been put in place in the euro area.

\section{The model}

Our model economy describes a monetary union that is comprised of two countries: Home and Foreign. The countries differ in terms of size and fiscal policy settings, but otherwise 
are symmetric. Consumers in Home and Foreign have the same preferences for bundles of differentiated goods. These goods are produced by firms in Home and Foreign, using Home and Foreign labor, respectively. Prices of individual goods are sticky, so that output is demand-determined.

As in Cúrdia and Woodford (2009, "CW" henceforth), we generate a need for financial intermediation by assuming that households can be either borrowers (that is, have a preference for early consumption) or savers. To keep the model analytically tractable, we posit that intermediaries operate in a competitive market at the union-wide level. They fund themselves through deposits that pay the same return everywhere, regardless of the saver's country of residence. By contrast, the market for loans is subject to country risk. In particular, the financial intermediaries' costs of lending to the resident of a particular member state rise with the costs of funding for the member state's sovereign. Thus, an increase in sovereign risk adversely affects private-sector borrowing conditions and depresses economic activity. ${ }^{10}$ These spillovers are at the heart of the "sovereign risk channel." Again for tractability, we make another assumption that reduces the heterogeneity across households. Specifically, households of a particular type and country of residence are assumed to join large families which pool the assets of their constituents. Finally, since macroeconomic dynamics generate fluctuations in the current account, we also make assumptions that ensure the stationarity of net foreign assets. In particular, we assume that in each period a fixed share of households in Home and Foreign are randomly selected to redraw not only their type (as in CW) but also their country of residence. ${ }^{11}$

As regards notation, where applicable, and unless noted otherwise, Home and Foreign variables are expressed per capita of the Home and Foreign population, respectively. Foreigncountry variables are indexed by an asterisk.

\footnotetext{
${ }^{10}$ This assumption is motivated by the empirical observation that, as sovereign default looms, domestic firms tend to face greater financial difficulties due to the risk of tax hikes, disruptive strikes, social unrest, and general economic turmoil, all of which may raise the challenge of monitoring and enforcing loan contracts.

${ }^{11}$ All households that are about to change type first pool their assets within their previous family. With their share of these assets, they then join a family that corresponds to their newly-drawn type and country of residence. Clearly, these modeling assumptions imply that there is some limited cross-country risk sharing, irrespective of government action. As far as the cross-country dimension is concerned, our approach complements the strategies to "close" open economy models discussed by Schmitt-Grohé and Uribe (2003), with a strategy adapted to models including borrowers and lenders following CW.
} 


\subsection{Households}

We assume that individual households differ in their preferences so that there is a role for financial intermediation within countries. Households are indexed by their type and their country of residence. Following CW, households can be borrowers (indexed by superscript b) or savers (indexed by $s$ ). Savers can put their savings into domestic government bonds or make one-period risk-free deposits with a union-wide financial intermediary. Borrowers obtain funds from financial intermediaries. Their borrowing rates are subject to countryspecific spreads.

Extending the mechanics of the $\mathrm{CW}$ model to a two-country framework, we assume that individual households' location changes stochastically over time. At each point in time, a fraction $\theta \in(0,1)$ of the population resides in Home, and the remaining $1-\theta$ households reside in Foreign. In each period, a share $(1-\delta), \delta \in(0,1)$, of household members change their type. Upon doing so, the type changers receive a transfer that depends on their past type. The transfers ensure that in equilibrium all type changers have the same wealth and thus the same ex-ante marginal utility. After the transfers have taken place, the type changers redraw their location and types. Type changers are assigned a country of residence as follows. $\theta$ is the probability of being assigned to Home. $1-\theta$ is the probability of being assigned to Foreign. Conditional on having been assigned to a country of residence, with probability $\pi_{b}$ the type changer ends up with a borrower's preferences. With the opposite probability $\pi_{s}=1-\pi_{b}$, the household ends up being a saver.

We assume that there is complete pooling of assets within households of a particular location and type ("family"). ${ }^{12}$ Note that the assumed type-changing mechanism partially insures households across types, by making changes in wealth levels temporary. Nevertheless, financial conditions will differ in the short and medium run, thus affecting the consumption and labor supply decisions of the different types of households.

Let $\tau \in\{(H, b),(H, s),(F, b),(F, s)\}$ capture the two characteristics of a household. As house-

\footnotetext{
${ }^{12}$ With positive government debt, assets of type changers will be positive on average. Therefore, if household members lived, saved, and borrowed on their own, newly-minted " $b$ "-types would have positive assets and, therefore, would not borrow immediately. For this reason, we cannot aggregate borrowers and savers with different histories the way that Cúrdia and Woodford (2009) do.
} 
holds supply labor only in the country where they reside, the utility of an individual household member is given by

$$
E_{0} \sum_{t=0}^{\infty} \beta^{t}\left[u_{\tau}\left(c_{t}^{\tau}, h_{t}^{\tau}\right)\right]
$$

where $\beta \in(0,1)$. Note that expectations are formed both about aggregate shocks and the future type. $h_{t}^{\tau}$ denotes hours worked by the household. Throughout, we will assume that $u_{\tau}\left(c_{t}^{\tau}, h_{t}^{\tau}\right)=\xi^{\tau} \frac{c_{t}^{\tau 1-1 / \sigma^{\tau}}}{1-1 / \sigma^{\tau}}-\psi^{\tau} \frac{h_{t}^{1+\nu}}{1+\nu}$, where $\xi^{\tau}, \sigma^{\tau}, \psi^{\tau}$, and $\nu$ are positive parameters.

The composite good $c_{t}^{\tau}$ is a bundle of, respectively, the Home-produced and Foreign-produced differentiated goods that a household of type $\tau$ consumes. Specifically, for each household $\tau$ the consumption index is given by

$$
c_{t}=\frac{c_{H, t}^{\theta} c_{F, t}^{1-\theta}}{\theta^{\theta}(1-\theta)^{1-\theta}}
$$

Here $c_{H, t}$ and $c_{F, t}$ are bundles of Home- and Foreign-produced intermediate goods, bundled according to the CES technology

$$
c_{H, t}=\left[\left(\frac{1}{\theta}\right)^{\frac{1}{\mu}} \int_{0}^{\theta} c_{H, t}(j)^{\frac{\mu-1}{\mu}} d j\right]^{\frac{\mu}{\mu-1}}, \quad c_{F, t}=\left[\left(\frac{1}{1-\theta}\right)^{\frac{1}{\mu}} \int_{\theta}^{1} c_{F, t}(j)^{\frac{\mu-1}{\mu}} d j\right]^{\frac{\mu}{\mu-1}},
$$

where $c_{H, t}(j)$ and $c_{F, t}(j)$ denote differentiated goods produced by firm $j \in[0,1]$ in Home and Foreign, respectively. $\mu>1$ denotes the price elasticity of demand for differentiated output goods. $P_{H, t}(j)$ and $P_{F, t}(j)$ are the prices denoted in the common currency of Home good $j$ and Foreign good $j$, respectively. We assume that the law of one price applies, so that consumers in Home and Foreign pay the same price for the same good. ${ }^{13}$ The price indices for Home and Foreign good bundles are defined as $P_{H, t}=\left((1 / \theta) \int_{0}^{\theta} P_{H, t}(j)^{1-\mu} d j\right)^{\frac{1}{1-\mu}}$ and $P_{F, t}=\left(1 /(1-\theta) \int_{\theta}^{1} P_{F, t}(j)^{1-\mu} d j\right)^{\frac{1}{1-\mu}}$. The consumer price index is given by

$$
P_{t}=P_{H, t}^{\theta} P_{F, t}^{1-\theta}
$$

\footnotetext{
${ }^{13}$ Note that a good is defined by both its country of production and its index $j$. In particular, good $j$ produced in Home and good $j$ produced in Foreign are different goods. They can, therefore, command different prices.
} 
The terms of trade are defined as the relative price of Home goods to Foreign goods

$$
\tau_{t}=P_{H, t} / P_{F, t}
$$

Saving and borrowing is intermediated by perfectly competitive union-wide financial intermediaries. Throughout the paper, we assume that these intermediaries do not default. At the beginning of the period, and before type changes have played out, the combined wealth (denoted in nominal terms and per capita of the domestic population) of Home households who are savers is given by

$$
A_{t}^{s-}=S_{t-1}^{p}\left(1+i_{t-1}^{d}\right)+\left(1-\vartheta_{t}\right) B_{t-1}^{g}\left(1+i_{t-1}^{g}\right)+T_{t}^{c} .
$$

$S_{t-1}^{p}$ denotes Home households' deposits at financial intermediaries at the end of the previous period. The deposits earn the deposit rate $i_{t-1}^{d}$. Savers may also hold their domestic government's debt $B_{t-1}^{g} \geq 0$. We depart from CW by assuming that, for the individual household, government debt is not risk-free: In any given period, the government may honor its debt obligations, in which case $\vartheta_{t}=0$; or it may partially default, in which case $\vartheta_{t}=\vartheta_{\text {def }}$, with $\vartheta_{\text {def }} \in(0,1)$ indicating the size of the haircut. $i_{t-1}^{g}$ is the notional interest rate on government debt.

The risk of default affects the portfolio decisions of savers, and thus the wedge between the risk-free rate, $i_{t}^{d}$, and the interest rate on government debt, $i_{t}^{g}$. This interest rate wedge, as discussed below, plays a crucial role, affecting the allocation even prior to an actual sovereign default. To focus on the sovereign risk channel, we abstract from the possible ex-post consequences of an actual default through appropriate assumptions. Specifically, we assume transfers $T_{t}^{c}$ that, in case of a sovereign default, compensate savers for the losses associated with the default (see Schabert and van Wijnbergen (2008) for a similar setup). These transfers do not affect investment decisions, as they are not proportional to the bond holdings of an individual saver. Formally, we set

$$
T_{t}^{c}=\vartheta_{t} B_{t-1}^{g}\left(1+i_{t-1}^{g}\right)
$$


Analogous to the case of savers discussed in equation (4), at the beginning of the period, before type changes have played out, the combined debt of Home households who are borrowers is given by

$$
A_{t}^{b-}=B_{t-1}^{p}\left(1+i_{t-1}^{b}\right)
$$

where $B_{t-1}^{p}$ denotes nominal private debt and $i_{t-1}^{b}$ denotes the Home borrowing rate. The beginning-of-period wealth of Foreign households is defined analogously. It bears noting that savers in Home and Foreign receive the same rate of interest $i_{t}^{d}$ on their deposits. As further specified below, we assume that this rate is the central bank's policy rate. By contrast, the rates of interest that borrowers are charged in the two countries may diverge.

Denote by $A_{t}^{\dagger}$ the beginning-of-period wealth of the pool of individuals who were selected to redraw their characteristics. Before they are randomly assigned a new type, the wealth of households in this pool is (in per capita terms):

$$
\begin{aligned}
A_{t}^{\dagger}= & \theta\left[S_{t-1}^{p}\left(1+i_{t-1}^{d}\right)+B_{t-1}^{g}\left(1+i_{t-1}^{g}\right)-B_{t-1}^{p}\left(1+i_{t-1}^{b}\right)\right] \\
& +(1-\theta)\left[S_{t-1}^{p *}\left(1+i_{t-1}^{d}\right)+B_{t-1}^{g *}\left(1+i_{t-1}^{g *}\right)-B_{t-1}^{p *}\left(1+i_{t-1}^{b *}\right)\right] \\
= & \theta B_{t-1}^{g}\left(1+i_{t-1}^{g}\right)+(1-\theta) B_{t-1}^{g *}\left(1+i_{t-1}^{g *}\right) .
\end{aligned}
$$

The first line provides the value of wealth contributed by Home households (selected to redraw their type). This is the amount of domestic assets net of domestic liabilities. The second line presents the same values for those who have previously resided in Foreign. The third line consolidates these items, anticipating the behavior of intermediaries as described by equation (18) further below.

The combined wealth of Home saver households at the end of the period, i.e., after type changes have taken place, is given by:

$$
S_{t}^{p}+B_{t}^{g}=\delta\left[S_{t-1}^{p}\left(1+i_{t-1}^{d}\right)+B_{t-1}^{g}\left(1+i_{t-1}^{g}\right)\right]-\pi_{s} X_{t}^{s}+\pi_{s}(1-\delta) A_{t}^{\dagger} .
$$

Here $X_{t}^{s}$ denotes expenditures of a saver household net of its nonfinancial income:

$$
X_{t}^{s}=P_{t} c_{t}^{s}-w_{t} P_{t} h_{t}^{s}-D_{H, t}^{f}-D_{t}^{i n t}+T_{t}^{g}
$$


Above, $w_{t}$ is the (Home) economy-wide real wage; $D_{H, t}^{f}$ are profits earned by goods-producing firms (again in per capita terms of the Home population). The ownership of these firms is assumed to remain domestic. $D_{t}^{\text {int }}$ are profits arising at the financial intermediaries. The intermediaries are assumed to be owned by Home and Foreign households in proportion to their respective population size. Last, $T_{t}^{g}$ are lump-sum taxes levied by the Home government. The combined end-of-period debt of Home borrower households (per capita of the Home population) is given by

$$
B_{t}^{p}=\delta B_{t-1}^{p}\left(1+i_{t-1}^{b}\right)+\pi_{b} X_{t}^{b}-\pi_{b}(1-\delta) A_{t}^{\dagger},
$$

Net expenditures for the borrower, $X_{t}^{b}$, are defined analogously to those for the saver. The Foreign terms are defined in the same way as those for Home households.

Turning to the intertemporal consumption decisions, note that, as a result of the family and pooling assumptions, all households of a specific type have a common marginal utility of real income, $\lambda_{t}^{\tau}$, and choose the same level of expenditure. For Home households, we have, for example,

$$
\begin{aligned}
\lambda_{t}^{s} & =\frac{\partial u_{s}\left(c_{t}^{s}, h_{t}^{s}\right)}{\partial c_{t}^{s}}, \\
\lambda_{t}^{b} & =\frac{\partial u_{b}\left(c_{t}^{b}, h_{t}^{b}\right)}{\partial c_{t}^{b}} .
\end{aligned}
$$

Similar relationships apply to Foreign households.

In Home, the optimal choices regarding borrowing from and lending to intermediaries, as well as to the government, are governed by the following Euler equations:

$$
\begin{aligned}
& \lambda_{t}^{s}=\beta E_{t}\left[\frac{1+i_{t}^{d}}{\Pi_{t+1}}\{\delta \lambda_{t+1}^{s}+(1-\delta) \underbrace{\left[\theta\left[\pi_{b} \lambda_{t+1}^{b}+\pi_{s} \lambda_{t+1}^{s}\right]+(1-\theta)\left[\pi_{b} \lambda_{t+1}^{b *}+\pi_{s} \lambda_{t+1}^{s *}\right]\right]}_{:=\bar{\lambda}_{t+1}}\}\right] \\
& \lambda_{t}^{s}=\beta E_{t}\left[\frac{\left(1-\vartheta_{t+1}\right)\left(1+i_{t}^{g}\right)}{\Pi_{t+1}}\left\{\delta \lambda_{t+1}^{s}+(1-\delta) \bar{\lambda}_{t+1}\right\}\right], \\
& \lambda_{t}^{b}=\beta E_{t}\left[\frac{1+i_{t}^{b}}{\Pi_{t+1}}\left\{\delta \lambda_{t+1}^{b}+(1-\delta) \bar{\lambda}_{t+1}\right\}\right] .
\end{aligned}
$$


The consumption Euler equations have the same structure for the Foreign households. Note, in particular, that the assumptions on partial risk sharing imply that for borrowers and savers, and Home and Foreign households, the continuation values share a common element $\left(\bar{\lambda}_{t+1}\right)$. In Home, optimal labor supply by each type of household, in turn, is given by

$$
\begin{aligned}
h_{t}^{s} & =\left(\frac{\lambda_{t}^{s}}{\psi^{s}} w_{t}\right)^{1 / \nu}, \\
h_{t}^{b} & =\left(\frac{\lambda_{t}^{b}}{\psi^{b}} w_{t}\right)^{1 / \nu},
\end{aligned}
$$

and again the same for Foreign households. Recall that, by assumption, households supply labor only in the country where they reside. Across household types, average labor supply, $h_{t}=\pi^{b} h_{t}^{b}+\left(1-\pi^{b}\right) h_{t}^{s}$, is given by

$$
h_{t}=\left(\frac{\Lambda_{t}}{\psi} w_{t}\right)^{1 / \nu}
$$

where

$$
\Lambda_{t}:=\psi\left[\pi^{b}\left(\frac{\lambda_{t}^{b}}{\psi^{b}}\right)^{1 / \nu}+\pi^{s}\left(\frac{\lambda_{t}^{s}}{\psi^{s}}\right)^{1 / \nu}\right]^{\nu}
$$

and $\psi^{-1 / \nu}=\pi^{b}\left(\psi^{b}\right)^{-1 / \nu}+\pi^{s}\left(\psi^{s}\right)^{-1 / \nu}$. Finally, for future reference we define

$$
\lambda_{t}=\pi^{b} \lambda_{t}^{b}+\left(1-\pi^{b}\right) \lambda_{t}^{s}
$$

as the average marginal utility of real income across types in the Home country.

\subsection{Financial intermediaries}

Savers and borrowers have access to area-wide perfectly competitive intermediaries. The intermediaries accept risk-free deposits, paying the interest rate $i_{t}^{d}$. This is the same interest rate that the intermediaries would need to pay in order to refinance themselves at the central bank. Borrowing conditions, instead, depend on the jurisdiction in which the borrower resides. As in CW, we assume that in each period a fraction of loans $\chi_{t}$ and $\chi_{t}^{*}$ cannot be recovered in Home and Foreign, respectively (due to, say, fraud). Intermediaries are assumed to collect the 
largest quantity of deposits that can be repaid with the proceeds of the loans they originate, that is,

$$
\left(1+i_{t}^{d}\right)\left(\theta S_{t}^{p}+(1-\theta) S_{t}^{p *}\right)=\left(1+i_{t}^{b}\right) \theta B_{t}^{p}+\left(1+i_{t}^{b *}\right)(1-\theta) B_{t}^{p *}
$$

Using $\omega_{t}$ as the spread between lending and deposit rates in Home, we have

$$
1+\omega_{t}:=\frac{1+i_{t}^{b}}{1+i_{t}^{d}}
$$

Choosing the amount of lending, $B_{t}^{p}$ and $B_{t}^{p *}$, to maximize profits, the first-order conditions for loan origination yield

$$
\omega_{t}=\chi_{t} \quad \text { and } \quad \omega_{t}^{*}=\chi_{t}^{*}
$$

In departing from CW, but following our own earlier work, Corsetti et al. (2013), we assume that $\chi_{t}$ and $\chi_{t}^{*}$ depend on sovereign risk in each country. This assumption is meant to capture the adverse effect of looming sovereign default risk on private-sector financial intermediation. Conceptually related is the notion that in the case of a sovereign default, the government diverts funds from the payments made by borrowers; see Mendoza and Yue (2012). Specifically, we assume that in Home

$$
\chi_{t}=\chi_{\psi}\left[\left(1+i_{t}^{g}\right) /\left(1+i_{t}^{d}\right)\right]^{\alpha_{\psi}}-1,
$$

where parameter $\chi_{\psi}>0$ is used to scale the private spread in the steady state, and $\alpha_{\psi} \geq 0$ measures the strength of the spillover from the $(\log )$ sovereign risk premium to the $(\log )$ private risk premium. In Foreign we have

$$
\chi_{t}^{*}=\chi_{\psi}^{*}\left[\left(1+i_{t}^{g *}\right) /\left(1+i_{t}^{d}\right)\right]^{\alpha_{\psi}^{*}}-1
$$

The spreads in Home and Foreign may thus differ. We allow for two distinct reasons: Either the yields on sovereign bonds in Home and Foreign differ, or the parameters that govern the spread $\left(\chi_{\psi}, \alpha_{\psi}\right.$ and $\left.\chi_{\psi}^{*}, \alpha_{\psi}^{*}\right)$ differ. Finally, while the intermediaries in equilibrium do not make profits, we have to take into account the transfers from intermediaries to households implied by loans that are not recovered by the intermediaries. Therefore, in accounting for 
the value of the intermediary to the households, $D_{t}^{\text {int }}=\omega_{t} \theta B_{t}^{p}+\omega_{t}^{*}(1-\theta) B_{t}^{p *}$.

\subsection{Firms}

In each of the two countries, there is a continuum of firms. Home firms are indexed by $j \in[0, \theta)$, Foreign firms by $j \in[\theta, 1)$. Each of these produces a differentiated good using linear technology

$$
y_{H, t}(j)=z h_{t}(j)
$$

where $z$ is the aggregate productivity level. In each period only a fraction $(1-\alpha)$ of firms are able to reoptimize their prices. Firms that do not reoptimize adjust their price by the steady-state rate of inflation, $\Pi$. Prices are set in period $t$ to maximize expected discounted future profits. The resulting first-order condition for a generic firm that adjusts its price, $P_{H, t}^{o p t}$, is given implicitly by

$$
F_{t}=K_{t}
$$

with

$$
\begin{aligned}
& K_{t}=\lambda_{t} \frac{\mu}{\mu-1} w_{t} \frac{y_{t}}{z}\left(\frac{P_{H, t}^{\mathrm{opt}}}{P_{H, t}}\right)^{-\mu}+\alpha \beta E_{t}\left(\frac{P_{H, t}^{\mathrm{opt}} \Pi}{P_{H, t+1}^{\mathrm{opt}}}\right)^{-\mu} K_{t+1}, \\
& F_{t}=\lambda_{t} y_{t}\left(\frac{P_{H, t}^{\mathrm{opt}}}{P_{H, t}}\right)^{1-\mu}\left(\frac{P_{H, t}}{P_{t}}\right)+\alpha \beta E_{t}\left(\frac{P_{H, t}^{\mathrm{opt}} \Pi}{P_{H, t+1}^{\mathrm{opt}}}\right)^{1-\mu} F_{t+1} .
\end{aligned}
$$

The law of motion for prices of the Home-produced basket $\left(\Pi_{H, t}:=P_{H, t} / P_{H, t-1}\right)$ is given by

$$
1-\alpha\left(\frac{\Pi}{\Pi_{H, t}}\right)^{1-\mu}=(1-\alpha)\left(\frac{P_{H, t}^{o p t}}{P_{H, t}}\right)^{1-\mu} .
$$

For future reference, it is also useful to define price dispersion of Home goods as $\Delta_{H, t}:=$ $\frac{1}{\theta} \int_{0}^{\theta}\left(\frac{P_{H, t}(j)}{P_{H, t}}\right)^{-\mu} d j$, which evolves according to

$$
\Delta_{H, t}=\alpha \Delta_{H, t-1}\left(\frac{\Pi_{H, t}}{\Pi}\right)^{\mu}+(1-\alpha)\left(\frac{P_{H, t}^{o p t}}{P_{H, t}}\right)^{-\mu} .
$$

Analogous expressions apply to the corresponding Foreign terms. Finally, nominal prof- 
its distributed to households by these firms are (in per capita terms) given by $D_{H, t}^{f}=$ $\frac{1}{\theta}\left[\int_{0}^{\theta} P_{H, t}(j) y_{H, t}(j)-P_{t} w_{t} h_{t}(j) d j\right] ;$ or, in equilibrium, $D_{H, t}^{f}=P_{H, t} y_{H, t}-P_{t} w_{t} h_{t}$. Here $y_{H, t}=\left[(1 / \theta) \int_{0}^{\theta} y_{H, t}(j)^{\frac{\mu-1}{\mu}} d j\right]^{\frac{\mu}{\mu-1}}$ denotes the per capita production of the bundle of differentiated goods produced in the Home country.

\subsection{Government}

In each country, the government finances a stream of exhaustive government spending, $g_{t}$, through lump-sum taxes or by issuing debt. Spending is isomorphic to private consumption and hence falls on both Home and Foreign goods. Per capita Home government debt evolves according to:

$$
B_{t}^{g}=\left(1-\vartheta_{t}\right) B_{t-1}^{g}\left(1+i_{t-1}^{g}\right)+P_{t} g_{t}+T_{t}^{c}-T_{t}^{g}
$$

In the sections further below, we will consider different assumptions regarding the law of motion for government spending, $g_{t}$.

Taking into account (5), the government flow budget constraint is given by

$$
B_{t}^{g}=B_{t-1}^{g}\left(1+i_{t-1}^{g}\right)+P_{t} g_{t}-T_{t}^{g}
$$

Regarding taxes, we assume that

$$
\frac{T_{t}^{g}}{P_{t}}-t^{g}=\phi_{T, y}\left(y_{H, t}-y_{H}\right)+\phi_{T, b^{g}}\left(b_{t-1}^{g}-b^{g}\right), \quad \phi_{T, y}>0, \phi_{T, b^{g}}>0 .
$$

Here and in the following, variables without a time subscript refer to steady-state values. $b_{t}:=B_{t} / P_{t}$ denotes the real value of debt, $t^{g}$ the real tax revenue in steady state. Tax revenue rises when economic activity improves, with parameter $\phi_{T, y}$ denoting the semi-elasticity of revenue with respect to output. Similarly, it rises whenever debt exceeds its target value. Throughout the paper, we assume that $\phi_{T, b^{g}}$ is large enough so as to eventually stabilize public debt.

While actual default ex post is neutral in the sense described above, the ex ante probability of 
default is crucial for the pricing of government debt $\left(i_{t}^{g}\right)$ and for real activity. ${ }^{14}$ In the current paper, as in our previous work, Corsetti et al. (2013), we operationalize sovereign default by appealing to the notion of a fiscal limit in a manner similar to Bi (2012). Whenever the debt level rises above the fiscal limit, default will occur. The fiscal limit is determined stochastically, capturing the uncertainty that surrounds the political process in the context of sovereign default. Specifically, we assume that in each period the limit will be drawn from a generalized beta distribution with parameters $\alpha_{b^{g}}, \beta_{b^{g}}$, and $\bar{b}^{\mathrm{g}, \max }$. As a result, the ex ante probability of default, $p_{t}$, at a certain level of sovereign indebtedness, $b_{t}^{g}$, will be given by the cumulative distribution function of the beta distribution as follows:

$$
p_{t}=F_{\text {beta }}\left(\frac{b_{t}^{g}}{4 y_{H}} \frac{1}{\bar{b}^{g, \max }} ; \alpha_{b^{g}}, \beta_{b^{g}}\right) .
$$

Note that $\bar{b}^{\text {g,max }}$ denotes the upper end of the support for the debt-to-GDP ratio. Regarding the haircut this implies

$$
\vartheta_{t}=\left\{\begin{aligned}
\vartheta_{\text {def }} & \text { with probability } p_{t} \\
0 & \text { with probability } 1-p_{t}
\end{aligned}\right.
$$

Turning to monetary policy, we assume throughout that the central bank follows a Taylor-type interest rate rule for the aggregate economy that also seeks to insulate aggregate economic activity from fluctuations in risk spreads. In particular, we assume:

$$
\begin{aligned}
\log \left(1+i_{t}^{d}\right)= & \log \left(1+i^{d}\right)+\phi_{\Pi}\left[\theta \log \left(\Pi_{t} / \Pi\right)+(1-\theta) \log \left(\Pi_{t}^{*} / \Pi\right)\right] \\
& -\phi_{\omega}\left[\theta \log \left(\left(1+\omega_{t}\right) /(1+\omega)\right)+(1-\theta) \log \left(\left(1+\omega_{t}^{*}\right) /(1+\omega)\right)\right] .
\end{aligned}
$$

Here, $\phi_{\Pi}>1, \phi_{\omega}>0$. We will assume below that the central bank, if possible, will set $\phi_{\omega}$ so as to neutralize the effect that the spreads $\omega_{t}$ and $\omega_{t}^{*}$ have on aggregate activity. ${ }^{15}$

\footnotetext{
${ }^{14}$ This implication of our setup is in line with evidence reported by Yeyati and Panizza (2011). Investigating output growth across a large number of episodes of sovereign default, they find that the output costs of default materialize in the run-up to defaults rather than at the time when the default actually takes place.

${ }^{15}$ For the closed economy, Cúrdia and Woodford (2009) show that optimal policy in the presence of credit frictions involves some adjustment of policy rates in response to interest rate spreads.
} 


\subsection{Market clearing}

Goods-market clearing at the level of intermediate goods requires that

$$
y_{H, t}(j)=\left(\frac{P_{H, t}(j)}{P_{H, t}}\right)^{-\mu}\left\{\left(\frac{P_{H, t}}{P_{t}}\right)^{-1}\left[\theta\left(c_{t}+g_{t}\right)+(1-\theta)\left(c_{t}^{*}+g_{t}^{*}\right)\right]\right\},
$$

where per capita consumption in Home and Foreign is given by $c_{t}=\pi_{b} c_{t}^{b}+\pi_{s} c_{t}^{s}$ and $c_{t}^{*}=$ $\pi_{b} c_{t}^{b *}+\pi_{s} c_{t}^{s *}$, respectively.

The supply of Home and Foreign output, in respective per capita terms, is given by

$$
y_{H, t} \Delta_{H, t}=z h_{t} .
$$

and

$$
y_{F, t} \Delta_{F, t}=z h_{t}^{*} .
$$

\section{A tractable special case of the model}

In this section, we derive a linear approximation of the model's equilibrium conditions for a tractable special case that yields intuitive analytical expressions. ${ }^{16}$ These expressions will be useful in setting up and interpreting our numerical experiments, conducted for a more general version of the model in Section 5 below.

As regards notation, in what follows a variable without a time subscript refers to the steadystate value. A tilde indicates deviation from the steady state. Hence, $\tilde{g}_{t}:=g_{t}-g$, and $\tilde{y}_{t}:=$ $y_{t}-y$. The variables that carry hats are defined as $\widehat{\Pi}_{t}:=\log \left(\Pi_{t} / \Pi\right), \widehat{\omega}_{t}:=\log \left(\left(1+\omega_{t}\right) /(1+\omega)\right)$, and $\widehat{i}_{t}^{d}:=\log \left(\left(1+i_{t}^{d}\right) /\left(1+i^{d}\right)\right)$. A bar over a variable indicates area-wide averages; for example, $\overline{\tilde{y}}_{t}:=\theta \tilde{y}_{t}+(1-\theta) \tilde{y}_{t}^{*}$.

\footnotetext{
${ }^{16}$ We closely follow Corsetti et al. (2013), extending our previous results for a closed economy to the case of two countries in a currency union.
} 


\subsection{Assumptions}

The tractable special case of our model is based on the following six additional assumptions. Assumption 1: The parameters are restricted such that only the current period's average interest rate spread enters the area-wide IS equation directly. ${ }^{17}$

The area-wide IS equation then links output to real government spending and to the effective real interest rate through

$$
\overline{\tilde{y}}_{t}-\overline{\tilde{g}}_{t}=E_{t} \overline{\tilde{y}}_{t+1}-E_{t} \overline{\tilde{g}}_{t+1}-\bar{\sigma}\left[\widehat{i}_{t}^{d}+\left(\pi_{b}+s_{\Omega}\right) \overline{\widehat{\omega}}_{t}-E_{t} \bar{\Pi}_{t+1}\right]
$$

Here $\bar{\sigma}=\pi_{b} \frac{c^{b}}{y} \sigma_{b}+\pi_{s} \frac{c^{s}}{y} \sigma_{s}$ is the average intertemporal elasticity of substitution, and $s_{\Omega}$ is defined in Footnote 17. Since $\pi_{b}+s_{\Omega}>0$, fluctuations in the private-sector spread can influence area-wide economic activity if they are not neutralized by monetary policy.

Assumption 2: The parameters are such that the credit spread does not enter the area-wide Phillips curve, which is thus given by:

$$
\overline{\widehat{\Pi}}_{t}=\beta E_{t} \overline{\widehat{\Pi}}_{t+1}+\kappa_{y} \overline{\tilde{y}}_{t}-\kappa_{g} \overline{\tilde{g}}_{t}
$$

where $\kappa_{y}:=\kappa\left(\nu+\bar{\sigma}^{-1}\right)$ and $\kappa_{g}:=\kappa \bar{\sigma}^{-1}$, with $\kappa:=\frac{(1-\alpha)(1-\alpha \beta)}{\alpha} .18$

Assumption 3: We assume that $\phi_{\omega}=\left(\pi_{b}+s_{\Omega}\right)$. Under this assumption, up to a first-order approximation, the central bank in normal times fully neutralizes the effect of the private credit spread on aggregate economic activity; see equations (33) and (37). Whenever this is the case, fluctuations in the sovereign risk premium do not affect aggregate economic activity either.

Assumption 4: We assume that producers in Home and Foreign face the same marginal costs. ${ }^{19}$ Under this assumption, the terms of trade will remain constant, which ensures that the solution remains tractable even if the two countries are asymmetric or show asymmetric fiscal responses.

\footnotetext{
${ }^{17}$ More formally, we assume that $s_{\Omega}(\bar{\delta}-1)=\psi_{\Omega}$. Here, $s_{\Omega}:=\pi_{b} \pi_{s}\left[\frac{c^{b}}{y} \sigma_{b}-\frac{c^{s}}{y} \sigma_{s}\right] / \bar{\sigma}, \psi_{\Omega}:=\pi_{b}\left(1-\chi_{b}\right)-$ $\pi_{s}\left(1-\chi_{s}\right)$, with $\chi_{\tau}=\beta \frac{R^{\tau}}{\Pi}\left\{\delta+(1-\delta) \pi_{\tau}\right\}$. Last, $\bar{\delta}:=\chi_{b}+\chi_{s}-1$.

${ }^{18}$ More formally, we assume that $\left[s_{\Omega}+\pi_{b}-\gamma_{b}\right]=0$ where $\gamma_{b} \equiv \pi_{b} \frac{h^{b}}{h}$.

${ }^{19}$ Labor subsidies/labor taxes can be introduced so as to achieve this.
} 
Assumption 5: The credit risk premium depends on the expected government deficit, rather than the expected level of government debt, according to the following relationship $\left(\pi_{b}+\right.$ $\left.s_{\Omega}\right) \widehat{\omega}_{t}=\xi E_{t}\left(\tilde{g}_{t+1}-\phi_{T, y} \tilde{y}_{t+1}\right)$, and $\left(\pi_{b}+s_{\Omega}\right) \widehat{\omega}_{t}^{*}=\xi^{*} E_{t}\left(\tilde{g}_{t+1}^{*}-\phi_{T, y} \tilde{y}_{t+1}^{*}\right)$. As specified in the previous section, parameter $\phi_{T, y} \in[0,1)$ measures the sensitivity of tax revenue with respect to economic activity. But here, in the tractable special case of our model, the parameter $\xi \geq 0$ indicates the extent to which a weak fiscal position - as measured by primary deficitsadversely affects private-sector spreads. Other things equal, high values of the parameter $\xi$ can be associated with an economy that has a high level of public debt and a correspondingly high responsiveness of the sovereign risk premium to a change in the fiscal outlook. ${ }^{20}$ Below, we allow for different slopes of the spread in the two countries, so that parameter $\xi$ need not equal $\xi^{*}$.

Under the assumptions above, the average spread that enters the area-wide IS equation (37) can be expressed as

$$
\left(\pi_{b}+s_{\Omega}\right) \overline{\widehat{\omega}}_{t}=\bar{\xi}\left(\overline{\tilde{g}}_{t+1}-\phi_{T, y} \overline{\tilde{y}}_{t+1}\right)+\theta(1-\theta) \xi^{D} \tilde{g}_{t+1}^{D}
$$

where $\bar{\xi}=\theta \xi+(1-\theta) \xi^{*}, \xi^{D}=\xi-\xi^{*}$, and $\tilde{g}_{t}^{D}:=\tilde{g}_{t}-\tilde{g}_{t}^{*}$. The average spread depends on the area-wide levels for output and government spending, and on the difference across countries in the level of government spending. ${ }^{21}$ Note that the average slope matters for the average risk premium (see the first term on the right-hand side of the equation above). Moreover, to the extent that the slopes differ $\left(\xi^{D} \neq 0\right)$, there may be scope for different policies in Home and Foreign (see second term).

Assumption 6: The policy rate, $\widehat{i}_{t}^{d}$, is fixed in the initial period, but, following Christiano et al. (2011) and Woodford (2011) monetary policy reverts to the Taylor rule $\widehat{i}_{t}^{d}=\phi_{\Pi} \overline{\widehat{\Pi}}_{t}-\phi_{\omega} \overline{\widehat{\omega}}_{t}$ in the next period with probability $1-\mu$, where $\mu \in(0,1)$. Otherwise, the interest rate remains constant. The same Markov structure applies to all subsequent periods. As a result, the expected length of the constant-interest-rate episode is given by $1 /(1-\mu)$.

\footnotetext{
${ }^{20}$ Section 3.2 in Corsetti et al. (2013) explicitly shows how $\xi$ relates to the debt level.

${ }^{21}$ There are no differences in per capita output in the two regions, by virtue of Assumption 4 .
} 


\subsection{Equilibrium determinacy}

We are now ready to examine the determinacy properties of the model for different fiscal policy configurations. The first proposition establishes parameter restrictions that yield a (locally) determinate equilibrium when government spending is determined exogenously in both countries.

Proposition 1 In the economy summarized by equations (37) - (39), where monetary policy is conducted according to assumption 6 above, let government spending in both countries be exogenously given. There is a locally unique bounded equilibrium if and only if

$$
\text { a) } a<1 /(\beta \mu) \text {, and b) }(1-\beta \mu)(1-a)>\mu \bar{\sigma} \kappa_{y} \text {, }
$$

where $a:=\mu+\mu \bar{\xi} \phi_{T, y} \bar{\sigma}$.

Proof. See Appendix C.1 of Corsetti et al. (2013).

Exactly as in our previous work for the closed economy, we find that the presence of a sovereign risk channel may undermine equilibrium determinacy in a monetary union. Specifically, conditions a) and b) are more likely to be violated if the average interest rate spread is sufficiently responsive to the government deficit (meaning $\bar{\xi}$, and thus $a$, is large enough).

Different from the closed-economy model, however, what matters for determinacy is the average slope of the risk premium in the union. Accordingly, a high sovereign risk premium affecting a sufficiently large part of the union can have systemically destabilizing effects, even if the rest of the union does not face elevated risk premia. At the same time, the fact that the risk premium is convex in sovereign debt suggests that pooling of government liabilities across borders may move the aggregate economy from an indeterminate to a determinate equilibrium. The main question is the extent to which, by reducing $\bar{\xi}$, debt pooling can fill in for the missing monetary response (that is, the fact that the central bank is cannot adjust the interest rate) during the initial period(s).

A second, related issue of interest is the extent to which, with or without pooling, determinacy can be fostered by a systematic government spending policy - which we abstracted from in Proposition 1. To address this question, we next allow the governments in Home and Foreign to adjust spending systematically in response to output movements.

In the first of our exercises, the policy response to output movements is symmetric across Home and Foreign. This exercise illustrates a potential benefit of austerity, namely, that 
procyclical spending cuts at the level of the union may contain the risk of indeterminacy (by increasing the region of parameters for which the equilibrium is determinate). Let area-wide government spending be given by $\overline{\tilde{g}}_{t}=\varphi \overline{\tilde{y}}_{t}$, and let each of the two countries conduct the same spending policy. ${ }^{22}$

Under this assumption, we have the following proposition.

Proposition 2 In the economy specified in Proposition 1, let government spending in Home and Foreign take on the same value $\tilde{g}_{t}=\tilde{g}_{t}^{*}=\varphi \overline{\tilde{y}}_{t}$ when the interest rate is held constant, and $\tilde{g}_{t}=\tilde{g}_{t}^{*}=0$ otherwise. Suppose further that $\varphi<1$. Define $a^{*}:=\mu+\mu \bar{\xi} \phi_{T, y}^{*} \bar{\sigma}^{*}$; $\phi_{T, y}^{*}:=\phi_{T, y}-\varphi ; \bar{\sigma}^{*}=\bar{\sigma} /(1-\varphi) ;$ and $\kappa_{y}^{*}=\kappa_{y}-\varphi \kappa_{g}$. There exists a locally unique bounded equilibrium if and only if:

1. with $a^{*} \geq 0$

$$
\text { a) } a^{*}<1 /(\beta \mu) \text {, and b) }(1-\beta \mu)\left(1-a^{*}\right)>\mu \bar{\sigma}^{*} \kappa_{y}^{*} \text {, }
$$

2. with $a^{*}<0$,

$$
\text { a) }(1+\beta \mu)\left(1+a^{*}\right)>-\mu \bar{\sigma}^{*} \kappa_{y}^{*} \text {, and }(1-\beta \mu)\left(1-a^{*}\right)>\mu \bar{\sigma}^{*} \kappa_{y}^{*} \text {. }
$$

Proof. See Appendix C.2 of Corsetti et al. (2013).

The most relevant implications are rather intuitive (compare Corollary 4 in Corsetti et al. (2013), which also applies here). Without the sovereign risk channel $(\bar{\xi}=0)$, the range of (nonpolicy) parameters for which the equilibrium is determinate is larger if area-wide government spending is countercyclical $(\varphi<0)$. With an endogenous risk premium, instead, the opposite may hold. Specifically, suppose that $\bar{\xi}>0$, the conditions of Item 1 of Proposition 2 hold, and taxes are not too elastic with respect to output $\left(\phi_{T, y}<1-\kappa \nu /(1-\beta \mu) \bar{\xi}\right)$. Then the range of fundamental parameters for which the equilibrium is determinate is at least as large with a procyclical spending response, $\varphi \in(0,1)$, as without any response, and can be strictly larger.

The main message is that, under certain circumstances, systematic spending cuts can help to anchor expectations to a unique equilibrium at a time when the central bank cannot adjust

\footnotetext{
${ }^{22}$ Note that the fiscal response function specified in our model is more general than might appear at first glance. Suppose, for example, that government spending would, instead, react to the primary deficit according to $\overline{\tilde{g}}_{t}=\gamma\left(\overline{\tilde{g}}_{t}-\phi_{T, y} \overline{\tilde{y}}_{t}\right)$. Under this rule, the higher $\gamma$, the more government spending would be expected to rise with the deficit. Now, for $\gamma<1$, and $\varphi<\phi_{T, y}$, there is a one-to-one mapping between the two rules' parameters, implying that a more countercyclical spending policy formulated in terms of output (a more negative $\varphi$ ) also maps into a more countercyclical policy in terms of the deficit (a higher $\gamma$ ), and vice versa.
} 
interest rates. Those circumstances are more likely to prevail when either the elasticity of tax revenue to economic activity $\left(\phi_{T, y}\right)$ is large, or the sensitivity of the interest rate spread to prospective deficits $(\bar{\xi})$ is high.

To see why, assume that, for given policy rates, agents develop arbitrary expectations of a drop in output. Lower output would mean less tax revenue and, in the absence of a fiscal response, higher deficits. In high-debt economies these deficits would imply a significantly higher interest rate spread. Since a widening of the interest rate spread is not (or cannot be) offset by monetary policy, the real interest rate would rise. A sharp rise in the real rate will weigh sufficiently on private demand to make nonfundamental expectations of adverse output developments self-fulfilling. In such a situation, a procyclical fiscal stance (insofar as it offsets the budgetary impact of the anticipated fall in tax revenue due to lower output) may prevent adverse expectational shocks from translating into a contraction in real economic activity. The following proposition synthesizes the result from a different exercise in which we allow government spending to react to output asymmetrically across countries. In particular, we assume that when one region pursues a countercyclical spending policy, the policy in the other region is procyclical. In order to illustrate as clearly as possible how asymmetric fiscal responses in Home and Foreign affect area-wide determinacy, we keep area-wide government spending constant in this exercise $\left(\overline{\tilde{g}}_{t}=0\right)$.

Proposition 3 In the economy specified in Proposition 1, let government spending in Home and Foreign take on values of $\tilde{g}_{t}=\Delta_{\varphi} \tilde{y}_{t}$ and $\tilde{g}_{t}^{*}=-\frac{\theta}{1-\theta} \Delta_{\varphi} \tilde{y}_{t}^{*}$ when the interest rate is held constant, and $\tilde{g}_{t}=\tilde{g}_{t}^{*}=0$ otherwise. Define $a^{* *}:=\mu+\bar{\sigma} \mu\left(\bar{\xi} \phi_{T, y}-\theta \xi^{D} \Delta_{\varphi}\right)$. There exists a locally bounded equilibrium if and only if:

1. with $a^{* *} \geq 0$ :

$$
\text { a) } a^{* *}<1 /(\beta \mu) \text {, and b) }(1-\beta \mu)\left(1-a^{* *}\right)>\mu \bar{\sigma} \kappa_{y} \text {, }
$$

2. with $a^{* *}<0$ :

$$
\text { a) }(1-\beta \mu)\left(1-a^{* *}\right)>\mu \bar{\sigma} \kappa_{y}, \quad \text { b) } \quad(1+\beta \mu)\left(1+a^{* *}\right)>-\mu \bar{\sigma} \kappa_{y} .
$$

Proof. See Appendix A.

The central implication of our proposition is summarized by Corollary 6 in the appendix. Suppose that the spread is more responsive to the deficit in Home than in Foreign, so that 
$\xi^{D}:=\xi-\xi^{*}>0$. Then, without changing the area-wide level of government spending, determinacy is more likely to be assured if fiscal austerity in Home (the higher-spread region) is combined with fiscal expansion in Foreign (the lower-spread region).

\subsection{The fiscal multiplier}

Having discussed how the sovereign risk channel influences equilibrium determinacy, it is worth touching on the implications for the fiscal multiplier, that is, the effects of exogenous variation in government spending on economic activity. In this section, as in Woodford (2011) and Christiano et al. (2011), we assume that parameters are such that the equilibrium is determinate, and we let government spending deviate from its steady-state level as long as policy rates remain constant. We establish that sovereign risk and its distribution across countries matter greatly for the size and the sign of the fiscal multiplier.

In our model, government spending affects economic activity through three different channels. First, it adds directly to aggregate demand, which, in the presence of nominal rigidities, drives economic activity. Second, as economic activity expands, marginal costs and inflation increase. At the ZLB (or with constant nominal rates), real interest rates decline and private expenditure rises (see Woodford 2011 and Christiano et al. 2011), implying a large fiscal multiplier. However, fiscal policy also has real effects through the sovereign risk channel: higher government spending may raise the deficit and thereby increase interest rate spreads, which, all else equal, depresses private expenditure. For the closed economy, this channel can partly or even fully offset the large fiscal multiplier at constant interest if sovereign risk is high; see Corsetti et al. (2013).

To the extent that the exogenous fiscal impulse is union-wide and symmetric, our simplified two-country setup is isomorphic to a closed economy, and the same result applies here: the multiplier may go toward zero and even turn negative if sovereign risk is very high at the union level (a high $\bar{\xi}$ ) and the expected duration of the constant-interest rate episode is not too short.

Next, we establish new results concerning the effects of asymmetric fiscal impulses. Specifically, we consider a scenario in which one country expands government spending by as much as the other country cuts it, so that the area-wide spending level is unaffected. 
Proposition 4 Under the conditions spelled out by Proposition 1 (which ensure that a locally unique bounded equilibrium exists), let Home government spending take on a value of $\tilde{g}_{t}=g_{L}$ while Foreign government spending takes on a value of $\tilde{g}_{L}^{*}=-\frac{\theta}{1-\theta} g_{L}$ as long as the interest rate is constant. Both Home and Foreign spending are equal to 0 otherwise. As before, define $a:=\mu+\mu \bar{\xi} \phi_{T, y} \bar{\sigma}$. Then, while the interest rate is fixed, output is given by

$$
\overline{\tilde{y}}_{L}=-\frac{\bar{\sigma} \mu \theta \xi^{D}}{1-a-\frac{\bar{\sigma} \mu \kappa_{y}}{1-\beta \mu}} g_{L} .
$$

Proof. See Appendix A.

Let $\xi^{D}>0$, that is, the spread is more responsive to the deficit in Home than it is in Foreign. In this case, a Home spending expansion and a simultaneous Foreign contraction have a negative effect on economic activity in the currency area. This effect comes about because (i) average government spending remains unchanged, so that there is no direct effect on aggregate demand in Home and Foreign; (ii) at the same time, however, the budgetary spending measure affects consumption more in the region with a more elastic risk premium (that is, Home, where a spending expansion raises deficits and thereby risk premia).

This result provides a warning against a scenario in which, perhaps under the presumption that austerity is self-defeating, high-debt countries adopt expansionary fiscal policies to which low-debt countries react with an offsetting budget contraction. Even abstracting from its potential consequences on determinacy (see Proposition 3 above), the overall impact of this policy mix would likely be undesirable. Indeed, aggregate activity would increase in the exact opposite scenario, where spending cuts occur in the country with the more elastic risk premium (Home), while the other country expands. In this case, again keeping area-wide government spending constant, a reduction in the average spread causes an expansion of activity in both regions. Our analysis thus suggests that coordinated fiscal packages, designed to internalize the asymmetric elasticity of risk premia to economic conditions, can be expansionary without necessarily altering the area-wide spending level.

Finally, we consider the case of a country-specific fiscal impulse. In particular, we assume that $\tilde{g}_{t}=g_{L}$ and $\tilde{g}_{t}^{*}=0$ during the constant-interest episode. As a result $\overline{\tilde{g}}_{t}=\theta g_{L}$. The following proposition states our result.

Proposition 5 Under the conditions spelled out by Proposition 1 (which ensure that a locally unique bounded equilibrium exists), let Home government spending take on a value of $\tilde{g}_{t}=g_{L}$ 
as long as the interest rate is constant, and 0 otherwise, while $\tilde{g}_{t}^{*}=0$ throughout. Then, during the period of constant interest rates, output is given by

$$
\overline{\tilde{y}}_{L}=\frac{1-\mu-\frac{\bar{\sigma} \mu \kappa_{g}}{1-\beta \mu}-\mu \bar{\sigma} \xi}{1-\mu-\mu \bar{\xi} \phi_{T, y} \bar{\sigma}-\frac{\bar{\sigma} \mu \kappa_{y}}{1-\beta \mu}} \theta g_{L} .
$$

Proof. A simple extension of the proof of Proposition 4.

This result illustrates that the effect of a unilateral fiscal impulse depends on both countryspecific and area-wide sovereign risk. To see this, note that the average spread enters the above expression in such a way that (as long as $\phi_{T, y}>0$, and determinacy is ensured) the denominator is strictly falling in $\bar{\xi}$. All else equal, the larger the average spread, the larger the effect of spending variation on area-wide economic activity, because higher tax revenues reduce interest rate spreads. At the same time, for a given fiscal expansion, the effect on area-wide activity declines with the extent of sovereign risk in the country that engineers the fiscal expansion ( $\xi$ in the numerator).

\section{$5 \quad$ Model simulations}

We now drop the simplifying assumptions of the previous section and turn to simulations of the full model outlined in Section 3. We aim to provide a quantitative analysis of key aspects of the euro area debt crisis, under alternative assumptions as regards spending and risk-pooling policies. Our results are based on a linear approximation of the equilibrium conditions of this model.

\subsection{Calibration}

We calibrate the model to the euro area. In the following, Home refers to the stressed economies, Foreign to the rest of the euro area. In terms of structural parameters we assume that both regions are isomorphic, except for fiscal policies and size: Home accounts for $\theta=1 / 3$ of the currency union, corresponding to the GDP weight of the stressed economies within the euro area. A time period in the model is one quarter. All nonfiscal parameters in our baseline parameterization are set assuming a ratio of government debt to (annual) GDP of 60 percent across both parts of the euro area, in line with the reference value in the Maastricht 
Table 3: Parameters

\begin{tabular}{llllllll}
\hline$\alpha$ & 0.925 & $\chi_{\psi}$ & 1.006 & $\phi_{T, y}$ & 0.500 & $\vartheta_{\text {def }}$ & 0.550 \\
$\alpha_{b^{g}}$ & 3.702 & $\delta$ & 0.950 & $\pi_{b}$ & 0.500 & $\theta$ & 0.333 \\
$\beta_{b^{g}}$ & 0.539 & $\mu_{p}$ & 1.150 & $\psi_{b}$ & 1.829 & $\xi_{b}$ & 0.296 \\
$\bar{b}^{g, \max }$ & 2.559 & $\nu$ & 0.526 & $\psi_{s}$ & 0.760 & $\xi_{s}$ & 0.104 \\
$\alpha_{\psi}$ & 0.550 & $\phi_{\Pi}$ & 1.500 & $\sigma_{s}$ & 1.307 & $\bar{\Pi}$ & 1.005 \\
$\beta$ & 0.991 & $\phi_{\omega}$ & 0.500 & $\sigma_{b}$ & 0.693 & $z$ & 3.000 \\
\hline
\end{tabular}

Notes: Parameters of the baseline calibration.

Treaty. When considering a higher initial stock of debt, we appropriately adjust steadystate tax revenue, the response of taxes to the debt level, $\phi_{T, b^{g}}$, and the level of government spending. The latter is set at 20 percent of each country's GDP. Table 3 lists the resulting parameterization.

As regards the parameters that govern the link between (strained) public finances and (elevated) private-sector spreads, we draw on global cross-country evidence. Actual haircuts in the case of a sovereign default show large variation; see Panizza et al. (2009) and Moody's Investors Service (2011). A 50-60 percent haircut appears to be a reasonable average value; so $\vartheta_{\text {def }}=0.55$. With respect to the specification of the fiscal limit, we set the parameters to $\alpha_{b^{g}}=3.70, \beta_{b^{g}}=0.54$, and $\bar{b}^{\text {g,max }}=2.56$. This parameterization follows Corsetti et al. (2013), who in turn choose these values to match the relationship between the sovereign risk premium, as measured by 5-year CDS spreads, and public debt in a sample of industrialized economies. As regards the spillovers from sovereign spreads to spreads in private credit markets that are at the heart of the sovereign risk channel, we follow the estimates in Harjes (2011) and set $\alpha_{\psi}=0.55$.

With respect to monetary policy, we assume an average inflation rate of 2 percent per year. The coefficient on inflation in the Taylor rule, which the central bank follows during normal times, is set to a customary value of $\phi_{\Pi}=1.5$. However, the economy does not start in normal times: in our baseline scenario, we assume that the interest rate is fixed in the initial period. In the following period, mimicking the Markov structure in Assumption 6 of Section 4.1 , it reverts to the rate prescribed by the Taylor rule with probability $\mu$. In the baseline, we set $\mu$ such that the policy rate is expected to be kept constant for 9 quarters. This value is consistent with data on Eonia OIS rates as of July 2012 (see Figure 3 above). With regard to the response of the interest rate to the private spread, we set $\phi_{\omega}=0.5$. The price stickiness parameter is fixed at $\alpha=0.925$. Judging by microeconomic evidence on price rigidities, 
the implied frequency of price adjustment may appear too low. However, our calibration implies an appropriately flat Phillips curve, causing inflation to respond relatively little to a recessionary shock, in line with the actual behavior of inflation during the latest crisis.

Regarding the other targets, we set productivity such that the steady-state output per capita in both parts of the euro area equals unity. We set the response of taxes to output to $\phi_{T, y}=0.5$. This appears to be reasonable for the relatively progressive tax systems of the euro area; see Girouard and André (2005). We assume that for each debt level, taxes react sufficiently strongly $\left(\phi_{T, b^{g}}\right.$ large enough), so that debt remains bounded throughout. Through that assumption we explicitly aim to rule out equilibria that follow the logic of the fiscal theory of the price level. Finally, for the spread between deposit and lending rates, we target a steady-state value for $\omega$ and $\omega^{*}$ of 2.5 percent (annualized). This corresponds to the average difference from 1999-2007 (thus pre-crisis) between the rate on new loans (for tenors of 1 to 5 years, up to EUR 1 million) and the Eonia rate. The steady-state level for the central bank's target interest rate, $i^{d}$, is set to be 4.5 percent (annualized).

We set the share of borrowers in the economy equal to $\pi_{b}=0.5$, as in Corsetti et al. (2013). We target a ratio of private debt to annual GDP, $b / 4 y$, of 130 percent, in line with average values (1999-2007) for debt in the nonfinancial private sector (loans, debt securities, and pension fund reserves). Households redraw their type on average every 20 quarters, meaning $\delta=0.95$. With regard to the preference parameters, we set the curvature of the disutility of work to $\nu=1 / 1.9$, in line with the arguments provided by Hall (2009). We target a gross price markup of $\mu^{p}=1.15$, which is in the range of values typically used in the literature. We also target a steady-state value for aggregate hours worked of $h=1 / 3$. As in Corsetti et al. (2013), we assume that the consumption-weighted average intertemporal elasticity of substitution takes a value of $\bar{\sigma}:=\pi_{b} \sigma_{b} c_{b}+\pi_{s} \sigma_{s} c_{s}=0.8$. We choose the relative values of the intertemporal elasticity of substitution for the two types of households $\left(\sigma^{b}\right.$ and $\left.\sigma^{s}\right)$ and of the scaling parameters for the disutility of work $\left(\psi^{b}\right.$ and $\left.\psi^{s}\right)$ such that (i) the above targets are satisfied; and (ii) for want of a better target, the steady-state consumption of the two types of households is the same. 


\subsection{Macroeconomic stability in the euro area}

The question that motivates our analysis is whether, under the conditions prevailing in mid2012, a sovereign crisis in the stressed economies of the euro area could expose the entire monetary union to the risk of a belief-driven downturn. According to the evidence discussed in Section 2, prior to any de facto pooling of sovereign risk through ESM and OMT, sovereign liabilities in the two regions amounted to 93 and 126 percent of GDP, respectively. Assuming full utilization of the scope provided by ESM and OMT, debt levels could effectively become equalized across regions. To gauge the impact of this hypothetical outcome, we consider a scenario where both regions have the same debt stock of some 104 percent of GDP.

Based on the results in Section 4, the consequences of sovereign risk on equilibrium determinacy cannot be evaluated independently of the future conduct of monetary and fiscal policy, which is subject to considerable uncertainty. In what follows, we therefore consider alternative assumptions. Regarding monetary policy, we report results for two different time horizons over which the central bank is expected to keep interest rates unchanged, i.e., 9 and 10 quarters. A duration of 9 quarters corresponds to our baseline case, but the financial market data in Figure 3 show that an even more extended ZLB period cannot be ruled out. Regarding fiscal policy, we vary assumptions about the fiscal stance in the two regions.

\subsubsection{Fiscal and monetary interaction}

We set the stage for our analysis by considering a pre-pooling policy scenario in which government spending exhibits a common stance across both parts of the euro area. This case is shown in the top row of Figure 4, for which debt in the rest of the euro area is held constant at 93 percent of GDP. The left and right panels show results for an expected ZLB episode of 9 and 10 quarters, respectively. In each panel, the horizontal axis measures the liabilities of the stressed economies over a wide range, including the 2012 value of 126 percent of GDP. On the vertical axis, a positive (negative) value indicates a common procyclical (countercyclical) fiscal stance. ${ }^{23}$ Formally, we capture the cyclical stance of spending through the parameter $\varphi$, such that $\tilde{g}_{t}=\varphi \tilde{y}_{t}$ and $\tilde{g}_{t}^{*}=\varphi \tilde{y}_{t}^{*}$. For the resulting parameter combinations we check whether the equilibrium is uniquely determined; the grey area represents the parameter space

\footnotetext{
${ }^{23}$ The evidence discussed in Section 2 suggests that, in the wake of the global financial crisis, both parts of the euro area pursued a procyclical stance, by implementing fiscal austerity in a downturn. A procyclical stance corresponds to $\varphi>0$.
} 
for which it is.

A first result of our analysis concerns the role of monetary and fiscal interaction. In the first row of the figure, absent any region-specific, endogenous spending response to output (hence along the horizontal line at $\varphi=0$ ), the equilibrium is determinate if the expected duration of the constant-interest-rate episode is 9 quarters, but indeterminate in the 10-quarter case. To assess the role of the sovereign risk channel in generating equilibrium indeterminacy for a given monetary policy, we counterfactually set debt equal to the Maastricht level of 60 percent of GDP in either country. In this case (not shown in the figure), the equilibrium would be determinate over a constant-interest-rate horizon up to 10 quarters. Loosely speaking, without systematic cyclical variation in spending, sovereign risk under our calibration of the model moves the frontier of indeterminacy problems forward by one quarter. ${ }^{24}$

In the graphs in the top row of Figure 4, the area above the zero line corresponds to a common procyclical spending stance, implying systematic cuts in a recession at the union level. Thus, a second result of our analysis is that a strongly procyclical spending stance gives rise to equilibrium indeterminacy, quite independently of the level of liabilities in the stressed economies. In our baseline with a constant-interest-rate period of 9 quarters, and debt in the stressed economies as high as 126 percent of GDP, the equilibrium would not be determinate for a value of $\varphi$ in excess of 0.4 . Note that in the simple model of the previous section, this threshold would still imply a cyclical deterioration of the primary surplus in a recession. The reason is that for $\varphi=0.4$ tax revenue is even more responsive to output than government spending.

While the recent developments in the euro area motivate the assumption of a similar fiscal stance across both parts of the euro area, it is instructive to consider alternative scenarios. Next, we therefore allow for the cyclical behavior of spending to differ systematically across regions. The panels in the middle row of Figure 4 refer to the case in which government spending is constant and hence acyclical in the rest of the euro area, whereas it comoves positively or negatively with economic activity in the stressed economies. Consequently, the area above the zero line now accounts for procyclical spending in the stressed economies only. The equilibrium is uniquely determined, independently of the fiscal stance in the stressed

\footnotetext{
${ }^{24}$ This result arguably understates the consequences of the sovereign risk channel, since we do not allow the horizon over which interest rates are constant to depend on fiscal conditions. In Corsetti et al. (2013), we model an endogenous exit from the ZLB. For that case, we find that sovereign risk tends to delay the exit from the ZLB, possibly by several quarters.
} 
Figure 4: Determinacy and endogenous spending policies
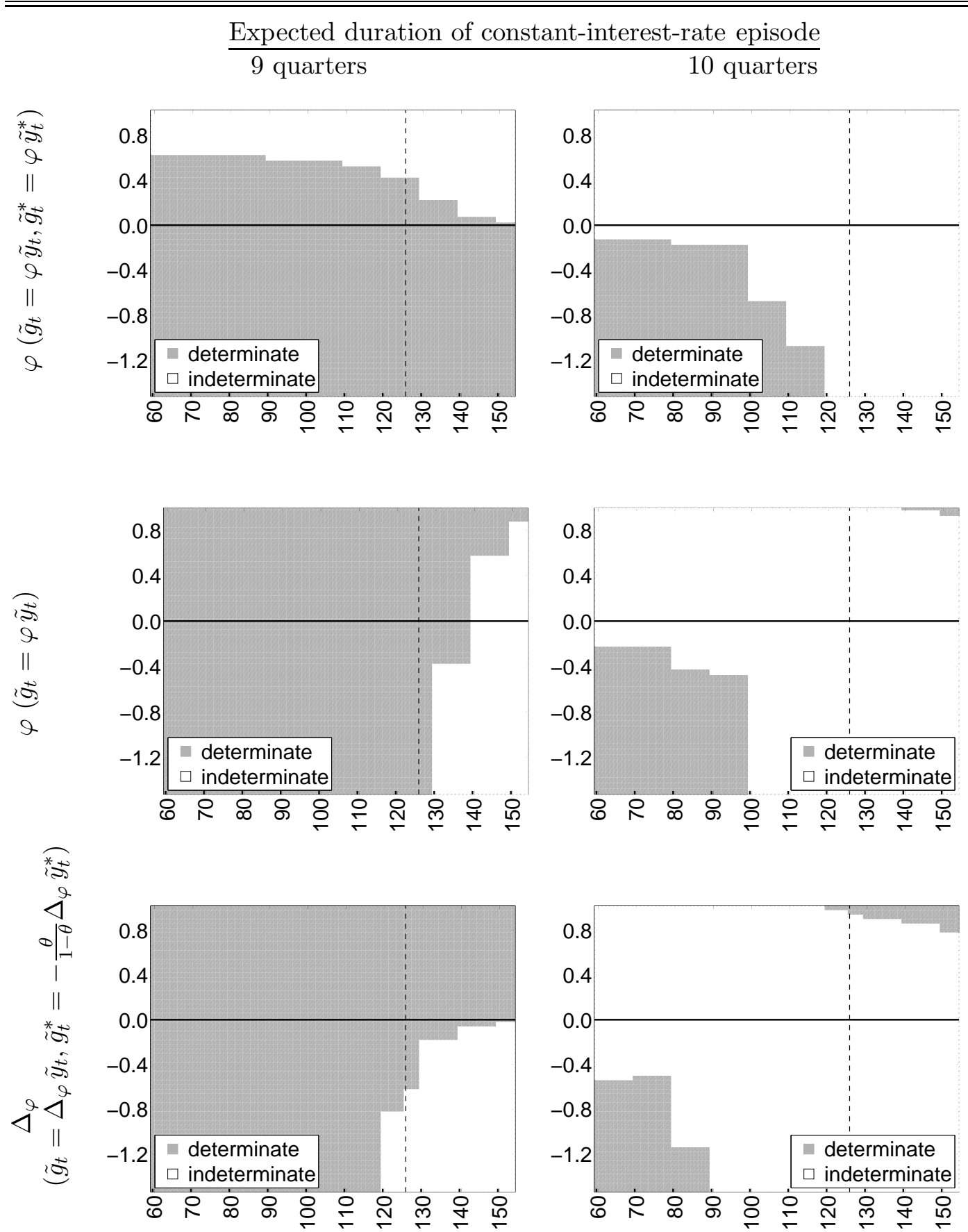

Debt in stressed economies

Debt in stressed economies

Notes: Determinacy regions for the case of an endogenous response of government spending to economic activity during a constant-interest-rate period. Grey areas mark parameterizations that imply determinacy. In the left panel, interest rates are expected to remain constant for 9 quarters, in the right panel for 10 quarters. x-axis: government debt level in the stressed economies (percent of their GDP). Debt in the rest of the euro area is assumed to be 92.5 percent of GDP. A vertical dashed line marks a debt level in the stressed economies of 126 percent of GDP. Top row: common fiscal stance $\varphi\left(\tilde{g}_{t}=\varphi \tilde{y}_{t}, \tilde{g}_{t}^{*}=\varphi \tilde{y}_{t}^{*}\right)$. Middle row: government spending in the rest of the euro area constant, y-axis: response of stressed economies' government spending to output in stressed economies $\varphi\left(\tilde{g}_{t}=\varphi \tilde{y}_{t}\right)$. Bottom arrow: y-axis measures differential response of government spending to output, $\Delta_{\varphi}\left(\tilde{g}_{t}=\Delta_{\varphi} \tilde{y}_{t}, \tilde{g}_{t}^{*}=39 \frac{\theta}{1-\theta} \Delta_{\varphi} \tilde{y}_{t}^{*}\right)$. 
economies, so long as their debt is below 130 percent of GDP. For debt levels above this threshold value, however, macroeconomic instability arises if the stressed economies pursue countercyclical spending expansions. Intuitively, high debt elevates the role for the sovereign risk channel. With a high sensitivity of risk premia to changes in government debt, expansionary spending plans in reaction to an economic slowdown exacerbate the vulnerability of the region to self-fulfilling expectations of a downturn.

Furthermore, macroeconomic instability looms large when the constant-interest-rate episode is expected to last longer. The middle-right panel refers to a 10-quarter horizon. At the 2012 debt level for the stressed economies, only a policy of very procyclical austerity in this region (with spending falling at least one for one with output) appears to be able to rule out self-fulfilling crisis dynamics (not shown in the panel). Hence, determinacy only prevails under extreme requirements on spending policy.

To save space, we omit the figure showing our results for the reverse exercise, which allows for cyclical spending policies in the rest of the euro area while keeping spending constant in the stressed economies. The picture is indeed similar to the upper panels of Figure 4. This finding resonates with our theoretical analysis in Section 4: provided that debt is not too high, the negative demand effects of procyclical spending cuts dominate the beneficial effect on interest rates. Conversely, a countercyclical stance in the rest of the euro area contributes to stability in the stressed economies by generating positive demand spillovers.

As a final step, we consider the case of asymmetries in the fiscal stance. In line with Proposition 3, we assess combinations of countercyclical and procyclical policies in the two parts of the euro area, such that aggregate spending remains constant at the union level. The results are shown in the lower panels of Figure 4. In these panels, the vertical axis measures the differential in the fiscal stance: positive values represent a procyclical stance in the stressed economies and a countercyclical stance in the rest of the euro area.

Overall, we find that the shape of the determinacy region is similar to the scenario with unilateral adjustment in government spending in the stressed economies (middle panels). That said, the size of the determinacy region shrinks somewhat in the bottom panels (which assume constant aggregate spending). Intuitively, the scope for policy mistakes increases: if one region pursues a policy that undermines stability, the other region - under our assumption - further exacerbates this. 
At high debt levels in the stressed economies, the combination of policies most likely to bring about a determinate equilibrium is a procyclical stance in the stressed economies coupled with a countercyclial stance elsewhere. To see why, suppose that markets come to believe, for nonfundamental reasons, that the stressed economies will experience a drop in economic activity. As discussed above, high sovereign risk means that such beliefs may easily become self-fulfilling. All else equal, spending cuts in the stressed economies reduce the deficit and thereby ease both sovereign risk and private-sector spreads. At the same time, the countercyclical stance in the rest of the euro area offsets the direct effect of spending cuts in the stressed economies on area-wide aggregate demand. All else equal, this stimulates economic activity and tax revenue in the stressed economies and thus contributes to averting a selffulfilling crisis. In fact, under our assumption of constant aggregate spending, the asymmetric fiscal stance in the rest of the euro area completely neutralizes the direct demand effects of spending cuts in the stressed economies, leaving the sovereign risk channel as the only relevant transmission mechanism.

\subsubsection{Risk pooling}

Insofar as sovereign risk premia increase nonlinearly in the level of debt, a pooling of liabilities (all else equal) induces a fall in the risk premium in the stressed economies that is only partially offset by higher risk premia in the rest of the euro area. In principle, as shown in Section 4, pooling can thus ensure determinacy by weakening the sovereign risk channel.

We now carry out our analysis assuming a common debt level at 104 percent of GDP, as would be implied by a complete equalization of debt levels in our illustrative pooling scenario. Under our calibration, this common debt level implies a reduction of the sovereign risk premium in the stressed economies by some 300 basis points relative to the pre-pooling scenario discussed above. $^{25}$

Figure 5 shows the results pertaining to the case of a common debt-to-GDP ratio and a common fiscal stance in both parts of the euro area. As in the previous figure, the two panels are drawn conditional on either a 9- or 10-quarter anticipated duration of the constantinterest-rate episode. In each panel, the common debt level is measured along the horizontal axis. The common fiscal stance, accounting for the way spending is systematically adjusted to

\footnotetext{
${ }^{25} \mathrm{~A}$ reduction of about 300 basis points was, in fact, observed during the late summer of 2012 , following the ECB's first hints at a new bond purchase program; see Figure 1 above.
} 
Figure 5: Determinacy regions (grey) - post-pooling

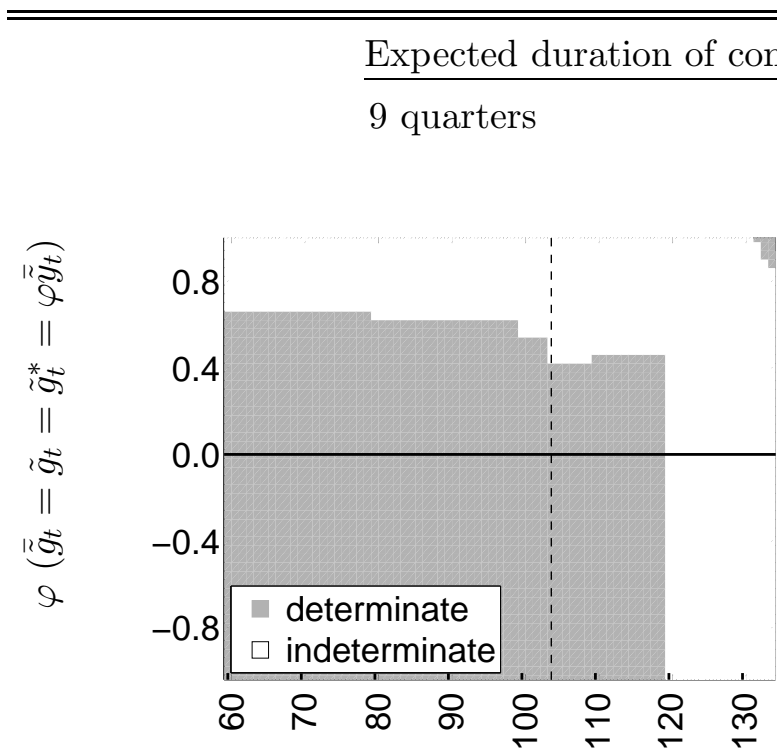

Debt

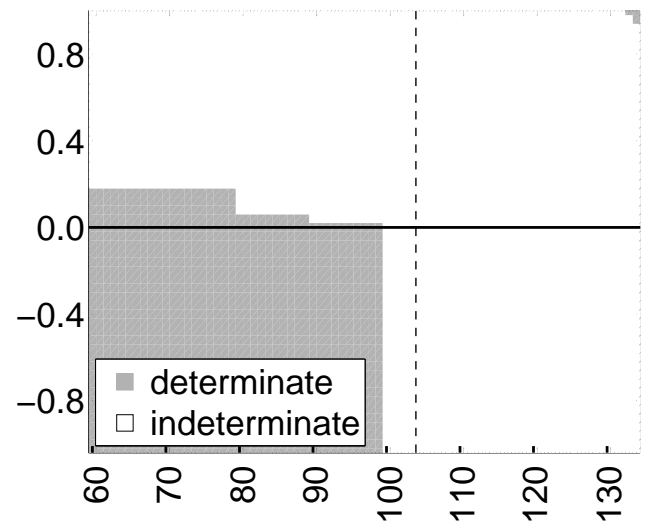

Debt

Notes: Determinacy regions for the case of an endogenous, symmetric response of government spending to economic activity during a constant-interest-rate period. Grey areas mark parameterizations that imply determinacy. y-axis: symmetric response of government spending to output, $\varphi\left(\overline{\tilde{g}}_{t}=\tilde{g}_{t}=\tilde{g}_{t}^{*}=\varphi \overline{\tilde{y}}_{t}\right)$. x-axis: government debt level (symmetric). A vertical dashed line marks a post-pooling debt-GDP level of 104.0 percent. In the left panel, interest rates are expected to remain constant for 9 quarters, in the right panel for 10 quarters.

output, is measured along the vertical axis. Once again, the grey area indicates combinations of parameters for which the equilibrium is determinate; the white area refers to indeterminacy. Not surprisingly, the implications of risk pooling for equilibrium determinacy are sensitive to the overall level of debt. When pooling results in a common debt-to-GDP ratio that is relatively low, determinacy is ensured if the spending policy at the union level is countercyclical or at most mildly procyclical. Intuitively, at moderate debt levels, the positive multiplier effect of government spending on aggregate demand dominates the effect of the sovereign risk channel. At high levels of debt, the opposite is true. In fact, determinacy at high levels of debt requires a strongly procyclical stance. In our calibration, the reversal occurs somewhere just below a debt-to-GDP ratio of 120 percent with 9 quarters of constant interest rates, and at 100 percent of GDP for the longer duration of 10 quarters.

Note that in our baseline scenario with a constant interest rate for 9 quarters, pooling of debt at 104 percent of GDP does not make the cyclical stance of spending any less relevant for macroeconomic stability compared to the pre-pooling scenario. Indeed, determinacy in 
the pooling scenario is assured only if fiscal policymakers in the union as a whole run a countercyclical or at best mildly procyclical spending policy. This finding suggests that a transfer of government liabilities across member states, in and by itself, would do little to address equilibrium indeterminacy under the conditions considered here.

\section{Conclusion}

Rising risk premia on government debt tend to drive up credit spreads in the private sector. When the central bank is constrained by the zero lower bound (ZLB) on policy rates, these spillovers from public to private spreads give rise to a sovereign risk channel that alters the trade-off between fiscal consolidation and support for economic activity. We integrate this sovereign risk channel in an otherwise standard New Keynesian two-country model and explore its implications for macroeconomic stability in a monetary union.

We calibrate the model to key features of the euro area as of mid-2012, distinguishing government debt levels across stressed and other economies. We show formally how the sovereign crisis in the stressed economies may threaten macroeconomic stability in the euro area as a whole, by exacerbating the risk of self-fulfilling expectations of a deflationary downturn. This result rests on the assumption that i) monetary policy is constrained for an extended period; and ii) both subgroups of euro area economies pursue procyclical policies during a recession - a policy scenario that strikes us as empirically relevant. By contrast, we also find that a (coordinated) asymmetric fiscal stance that combines procyclical cuts in the stressed (high-debt) economies with countercyclical expansion in the other (lower-debt) countries is conducive to macroeconomic stability.

Building on this analysis, we consider the potential pooling of sovereign risk, as implied by recent institutional initiatives within the euro area, notably the European Stability Mechanism (ESM) and the ECB's Outright Monetary Transactions (OMT). Since risk premia increase nonlinearly in debt, risk pooling reduces the strength of the sovereign risk channel. Even so, our simulations suggest that pooling per se does not alleviate the threat to macroeconomic stability arising from beliefs-driven fluctuations as long as the union-wide fiscal stance remains largely procyclical. Thus, the most critical aspect of policy coordination turns out to be the interaction between (constrained) monetary policy at the level of the currency union and the cyclicality of fiscal policy in the constituent parts. 
In our model, debt pooling generates a fall in spreads, in line with the actual stabilization of financial market conditions in the euro area since the introduction of ESM and OMT. Our analysis cautions against viewing this fall in spreads as evidence that debt pooling alone contributes much to making the euro area robust to beliefs-driven fluctuations. We wish to emphasize, however, that there are other interpretations of the ECB's OMT framework, which work through a change in monetary policymakers' behavior on or off the equilibrium path instead of through debt pooling. These different dimensions may have contributed significantly to macroeconomic stabilization; see the recent contributions by Aguiar et al. (2012) and Corsetti and Dedola (2013) on the role of a monetary backstop to rule out multiple equilibria.

The transmission mechanism we analyze in this paper emphasizes the adverse effects on current output of expectations of a possible sovereign default in the future. For the sake of tractability, we model the sovereign risk channel using empirically motivated reduced-form relationships between the fiscal outlook and risk premia on public and private debt. As a way forward, a model accounting for endogenous default under imperfect policy credibility might improve our understanding of how these relationships are shaped by actual policy trade-offs between distortions caused by taxes and inflation, output stabilization, and (endogenous) default costs. Such an extension of our model could contribute a monetary perspective to recent research (see, for instance, Mendoza and Yue 2012) that examines the endogenous output effects of sovereign debt crises in fully-fledged models of fiscal policymaking. 


\section{References}

Acharya, V. V., Drechsler, I., and Schnabl, P. (2013), 'A Pyrrhic Victory? Bank Bailouts and Sovereign Credit Risk,' mimeo, NYU-Stern.

Aguiar, M., Amador, M., Farhi, E., and Gopinath, G. (2012), 'Crisis and Commitment: Inflation Credibility and the Vulnerability to Sovereign Debt Crises,' mimeo.

Albertazzi, U., Ropele, T., Sene, G., and Signoretti, F. M. (2012), 'The impact of the sovereign debt crisis on the activity of Italian banks,' Questioni di economia e finanza, Banca d'Italia.

Arellano, C. (2008), 'Default Risk and Income Fluctuations in Emerging Economies,' American Economic Review, 98, pp. 690-712.

Arslanalp, S. and Liao, Y. (2012), 'Contingent Liabilities and Sovereign Risk: Evidence from Banking Sectors,' mimeo.

Bi, H. (2012), 'Sovereign Default Risk Premia, Fiscal Limits, and Fiscal Policy,' European Economic Review, 56, pp. 389-410.

Calvo, G. A. (1988), 'Servicing the Public Debt: The Role of Expectations,' American Economic Review, 78(4), pp. 647-661.

Cavallo, E. and Valenzuela, P. (2007), 'The Determinants of Corporate Risk in Emerging Markets: An Option-Adjusted Spread Analysis,' IADB Working Paper.

Christiano, L., Eichenbaum, M., and Rebelo, S. (2011), 'When Is the Government Expenditure Multiplier Large?' Journal of Political Economy, 119(1), pp. 78-121.

Cole, H. L. and Kehoe, T. J. (2000), 'Self-Fulfilling Debt Crises,' Review of Economic Studies, $67(1)$.

Corsetti, G. and Dedola, L. (2013), 'The mystery of the printing press: self-fulfilling debt crises and monetary sovereignty,' CEPR Discussion Paper 9358.

Corsetti, G., Kuester, K., Meier, A., and Müller, G. (2013), 'Sovereign Risk, Fiscal Policy, and Macroeconomic Stability,' Economic Journal, 123, pp. F99-F132.

Cúrdia, V. and Woodford, M. (2009), 'Credit Frictions and Optimal Monetary Policy,' Unpublished manuscript, Federal Reserve Bank of New York and Columbia University.

Eaton, J. and Gersovitz, M. (1981), 'Debt with Potential Repudiation: Theoretical and Empirical Analysis,' Review of Economic Studies, 48, pp. 289-309.

ECB (2012), 'Financial Stability Review, December 2012,' Frankfurt am Main, Germany.

ESM (2013), 'Factsheet,' Available at http://www.esm.europa.eu/pdf/ESM

Girouard, N. and André, C. (2005), 'Measuring Cyclically-Adjusted Budget Balances for OECD Countries,' OECD Economics Department Working Paper No. 434. 
Hall, R. (2009), 'By How Much Does GDP Rise If the Government Buys More Output?' Brookings Papers on Economic Activity, 2, pp. 183 - 231.

Harjes, T. (2011), 'Financial Integration and Corporate Funding Costs in Europe After the Financial and Sovereign Debt Crisis,' in: 'IMF Country Report No. 11/186,' International Monetary Fund.

IMF (2013), 'Global Financial Stability Report, April 2013,' Washington, D.C.

Kollmann, R., Roeger, W., and in’t Veld, J. (2012), 'Fiscal Policy in a Financial Crisis: Standard Policy versus Bank Rescue Measures,' American Economic Review, 102(3), pp. $77-81$.

Lane, P. R. (2012), 'The European Sovereign Debt Crisis,' Journal of Economic Perspectives, 26(3), pp. 49-68.

Mendoza, E. and Yue, V. (2012), 'A General Equilibrium Model of Sovereign Debt Default and Business Cycles,' Quarterly Journal of Economics, 127, pp. 889-946.

Moody's Investors Service (2011), 'Sovereign Default and Recovery Rates, 1983-2010,' May $10^{\text {th }}$.

Neri, S. (2013), 'The Impact of the Sovereign Debt Crisis on Bank Lending Rates in the Euro Area,' mimeo, Banca d'Italia.

Neri, S. and Ropele, T. (2013), 'The Macroeconomic Effects of the Sovereign Debt Crisis in the Euro Area,' mimeo, Banca d'Italia.

Panizza, U., Sturzenegger, F., and Zettelmeyer, J. (2009), 'The Economics and Law of Sovereign Debt and Default,' Journal of Economic Literature, 47, pp. 651-698.

Schabert, A. and van Wijnbergen, S., 'Sovereign Default and the Stability of Inflation Targeting Regimes,' (2008), mimeo, University of Amsterdam.

Schmitt-Grohé, S. and Uribe, M. (2003), 'Closing small open economy models,' Journal of International Economics, 61, p. 163185.

Woodford, M. (2003), Interest and Prices, Princeton University Press, Princeton, NJ.

Woodford, M. (2011), 'Simple Analytics of the Government Expenditure Multiplier,' American Economic Journal: Macroeconomics, 3, pp. 1 - 35.

Yeyati, E. and Panizza, U. (2011), 'The Elusive Costs of Sovereign Defaults,' Journal of Development Economics, 94(1), pp. 95-105.

Zoli, E. (2013), 'Italian Sovereign Spreads: Their Determinants and Pass-through to Bank Funding Costs and Lending Conditions,' IMF Working Paper 13/84. 


\section{A Proofs of propositions}

This appendix collects the proofs to the propositions in the main text. The appendix also presents the corollaries and their proofs.

\section{A.1 Proof of Proposition 3}

The economy, stripped of exogenous variables, is given by

$$
E_{t} z_{t+1}=A z_{t}
$$

where $z_{t}=\left[\overline{\tilde{y}}_{t} ; \bar{\Pi}_{t}\right]$. In this case

$$
A=\frac{1}{a^{* *} \mu \beta}\left[\begin{array}{cc}
\beta \mu+\tilde{\sigma} \mu \kappa_{y} & -\tilde{\sigma} \mu \\
-a^{* *} \kappa_{y} & a^{* *}
\end{array}\right],
$$

where $a^{* *}$ is defined in the proposition. ${ }^{26}$ The Blanchard-Kahn conditions for determinacy require that matrix $A$ have two roots outside the unit circle. Woodford (2003), pp. 670f., gives the following necessary and sufficient conditions for determinacy:

either (Case I): (i) $\operatorname{det}(A)>1$, (ii) $\operatorname{det}(A)-\operatorname{tr}(A)>-1$, and (iii) $\operatorname{det}(A)+\operatorname{tr}(A)>-1$, or (Case II): (i) $\operatorname{det}(A)-\operatorname{tr}(A)<-1$ and (ii) $\operatorname{det}(A)+\operatorname{tr}(A)<-1$.

1. If $a^{* *}>0, \operatorname{det}(A)>0$, so only Case I can be satisfied. Conditions (i) and (ii) of that case correspond to conditions a) and b) in Proposition 3. Since $\operatorname{tr}(A)>0$, condition (iii) of Case I is also satisfied.

2. For $a^{* *}<0, \operatorname{det}(A)<0$, so Case I cannot hold. The conditions given in the proposition are those pertaining to Case II with $a^{* *}<0$.

\section{A.2 Proof of Proposition 4}

The assumed Markov structure means that output and inflation (in deviations from the steady state) will take on the same respective values, $\overline{\tilde{y}}_{L}$, and $\overline{\hat{\Pi}}_{L}$ in every period in which monetary policy is constrained, and values of zero thereafter.

The Phillips curve gives

$$
\overline{\hat{\Pi}}_{L}=\frac{\kappa_{y}}{1-\beta \mu} \overline{\tilde{y}}_{L}
$$

Use this, and the terms for the spread in the IS equation:

$$
\left[1-a-\frac{\bar{\sigma} \mu \kappa_{y}}{1-\beta \mu}\right] \overline{\tilde{y}}_{L}=-\bar{\sigma} \mu \xi^{D} \theta g_{L}
$$

The term in square brackets is strictly positive per condition b) for determinacy in Proposition 1. Solving for $y_{L}$ yields the expression given in the proposition.

\footnotetext{
${ }^{26}$ Here we assume that $a^{* *} \neq 0$. Establishing the conditions for determinacy for $a^{* *}=0$ is straightforward.
} 


\section{B Statement and proof of Corollary 6}

Corollary 6 Under the conditions of Proposition 3, suppose that $\xi^{D}:=\xi-\xi^{*}>0$, so that the Home spread is more responsive to the Home deficit than the Foreign spread is to the Foreign deficit. Then, the range of fundamental parameters (that is, parameters other than $\left.\Delta_{\varphi}\right)$ for which the equilibrium is determinate is at least as large with a suitable choice of $\Delta_{\varphi}>0$ (that is, procyclical spending policy in Home and countercyclical spending policy in Foreign) as in the absence of an endogenous spending response, and can be strictly larger.

Proof. Absent a fiscal response, $a^{* *}>0$, which makes item 1 of Proposition 3 the relevant point of departure. $\frac{\partial a^{* *}}{\partial \Delta_{\varphi}}<0$. A positive value of $\Delta_{\varphi}$, chosen such that $a^{* *}$ will remain positive, means that condition (i) holds for a bigger set of fundamental parameters than with $\Delta_{\varphi}=0$. The same is true for condition (ii). 